\title{
IEA Wind Task 36
}

Gregor Giebel, DTU Wind Energy

W. Shaw, H. Frank, C. Möhrlen, C. Draxl, J. Zack, P. Pinson, G. Kariniotakis, R. Bessa EGU Online 2020 (c) (i)

Technology Collaboration Programme by lea $E$ 


\section{Overview}

News from IEA Wind Task 36 on Forecasting:

- Meteo benchmark coming up, info portal continuously updated

- End-user workshop in Glasgow

- Games motivating probabilistic information use

Additional material the Annex:

- What is the International Energy Agency?

- What is short-term prediction of wind power?

- What is the role and setup of IEA Wind Task 36?

- Achievements: Information portal, Recommended Practice, papers, handouts 


\section{Task Objectives \& Expected Results}

Task Objective is to encourage improvements in:

1) weather prediction

2) power conversion

3) use of forecasts

Task Organisation is to encourage international collaboration between:

$\rightarrow$ Research organisations and projects

$\rightarrow$ Forecast providers

$\rightarrow$ Policy Makers

$\rightarrow$ End-users and stakeholders

Task Work is divided into $\mathbf{3}$ work packages:

WP1: Weather Prediction Improvements

WP2: Power and Uncertainty Forecasting

WP3: Optimal Use of Forecasting Solutions

Current Term: 2019-2021 (Firsterm 2016-2018) 


\section{WP1 Meteorology Current state-of-the-Art}

- Verification\&Validation benchmark defined (US results to be published end of June, benchmark to be published on Atmosphere2Electrons (A2E) site)

- Continuously updating the lists, and work underway to use the collected data sets for Numerical Weather Prediction

\begin{tabular}{|c|c|c|c|c|c|c|c|c|c|}
\hline SITE NAME & COORDINATES & $\begin{array}{l}\text { ALTTUDE } \\
\text { ABOVE } \\
\text { MSL }\end{array}$ & $\begin{array}{l}\text { TOWER } \\
\text { HEIGHT }\end{array}$ & URL & CONTACT & DATA POLICY & $\begin{array}{l}\text { DATA } \\
\text { FORMAT }\end{array}$ & $\begin{array}{l}\text { OBS. } \\
\text { PERIOD }\end{array}$ & OTHER \\
\hline Cabauw, NL & $\begin{array}{l}4.926^{\circ} \mathrm{E} \\
51.97^{\circ} \mathrm{N}\end{array}$ & $-0.7 \mathrm{~m}$ & $200 \mathrm{~m}$ & unw.cesar-observatory.nlindex.php & henk.klein.baltink@knmi.nl & Cesar data policy & netCDF & $\begin{array}{l}2000-04-01 \\
\text { to previous } \\
\text { month }\end{array}$ & \\
\hline $\begin{array}{l}\text { IJmuiden, } \\
\text { NL }\end{array}$ & $\begin{array}{l}3.436^{\circ} \mathrm{N} \\
52.848^{\circ} \mathrm{E}\end{array}$ & $0 \mathrm{~m}$ & $92 \mathrm{~m}$ & $\begin{array}{l}\text { www.meteomastijmuiden.nl/en } \\
\text { Imeasurement-campaianl }\end{array}$ & verhoef@ecn.nl & & & since 2012 & $\begin{array}{l}\text { offshore North } \\
\text { Sea }\end{array}$ \\
\hline Risø, DK & $\begin{array}{l}12.088^{\circ} \mathrm{E} \\
55.694^{\circ} \mathrm{N}\end{array}$ & $0 \mathrm{~m}$ & $125 \mathrm{~m}$ & $\begin{array}{l}\frac{\text { rodeo.dtu.dkrodeo }}{\text { Projectoverview.aspx? \&Project }=5 \&} \\
\text { Rnd }=975820\end{array}$ & Allan Vesth & Ask nicely & & $\begin{array}{l}1995-11-20 \\
-\end{array}$ & $\begin{array}{l}\text { Data measured } \\
\text { since 1958; } \\
\text { some months } \\
\text { break in } 2008 .\end{array}$ \\
\hline Østerild, DK & $\begin{array}{l}8.88080^{\circ} \mathrm{E} \\
57.04888^{\circ} \mathrm{N}\end{array}$ & $9 \mathrm{~m}$ & $250 \mathrm{~m}$ & 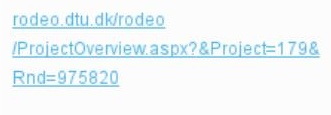 & Yoram Eisenberg & Ask nicely & & $\begin{array}{l}2015-01-28 \\
-\end{array}$ & $\begin{array}{l}\text { Two } 250 \mathrm{~m} \\
\text { masts in } 4.3 \mathrm{~km} \\
\text { distance, both } \\
\text { instrumented. }\end{array}$ \\
\hline
\end{tabular}




\section{WP2 IEA Recommended Practice on Forecast Solution Selection}

- Received feedback from industry, use of some concepts starts to appear in tenders

- Requires more dissemination, e.g. on Hybrid systems workshop

- Version Update (2021):

- More input from industry

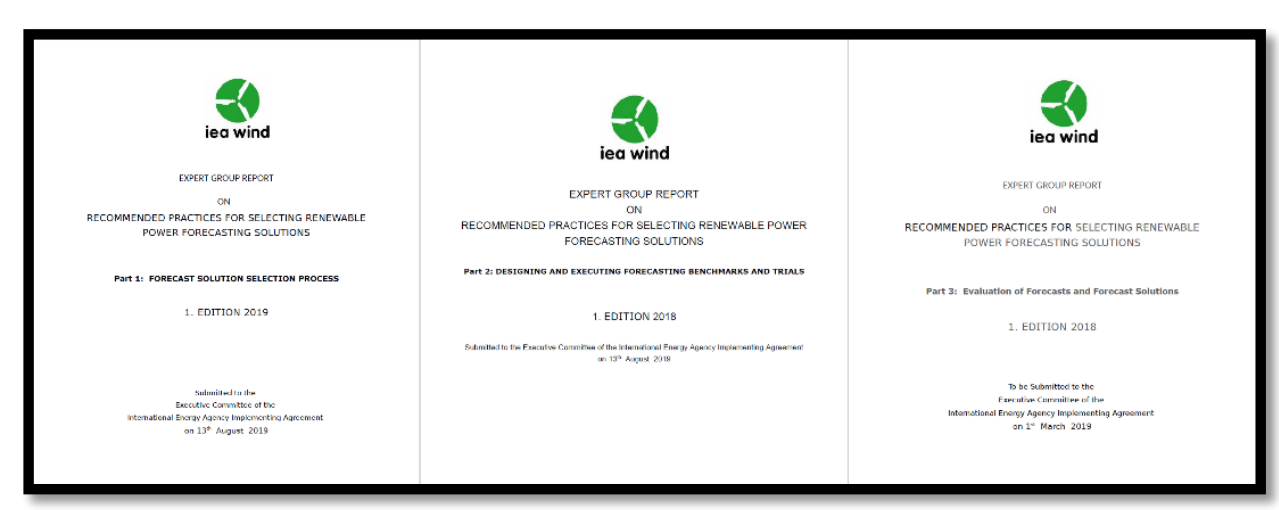

- Filling in found omissions

- More examples

- Collaboration with IEA Solar Task 


\section{WP3 Optimal Use of Forecasting Solutions}

- Definition of forecast error spread / confidence intervals vs forecast uncertainty

- Continued collaboration with IEC SC 8A Workgroup on Technical Report IEC63043

- Standardisation of meteorological data feeds and instrumentation for forecasting

- Value of forecasts: investigation started by analysis (ppt, paper underway) and forecast game/experiment:

https://mpib.eu.qualtrics.com/ife/form/SV d5aAY95q2mGI8El

(feel free to play it yourself - it's still open !) 


\section{WP3 End-user Workshop in Glasgow}

"Maximising Value from State-of-the-art Wind Power Forecasting Solutions" hosted by Jethro Browell at Strathclyde University, Glasgow, 21 Jan 2020

- Talks by academia and industry (e.g. UK National Grid, WindPoint, UStrathclyde )

- Open Space discussion on RP, data and forecast value

- Game on value of probabilistic forecasts (feel free to play it - it's still open !): https://mpib.eu.qualtrics.com/jfe/form/SV d5aAY95q2mGI8El

- Streamed on YouTube: https://www.youtube.com/watch?v=1NOIr7jluXI

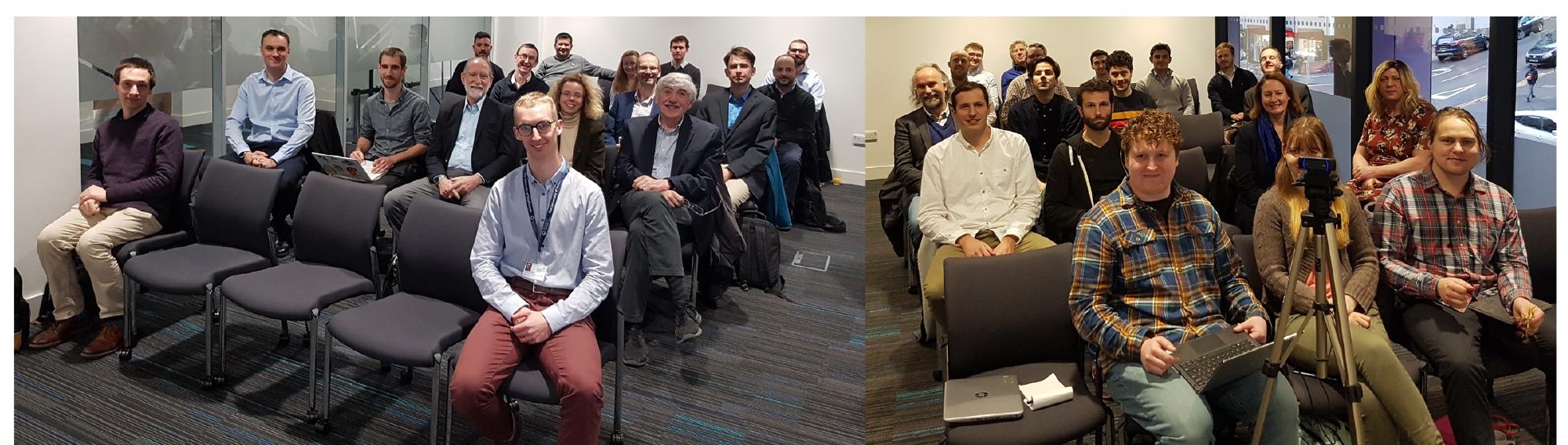




\section{Postulates formed the basis for the experiment design:}

(1) Success in the trading is highly dependent on the costs of the balancing power needed due to forecast errors

(2) $5 \%$ of the cases, where there are large forecast errors are responsible for $95 \%$ of the costs in a month or year

(3) Reducing these costs is more important than improving the general forecasts by $\sim 1 \%$

\section{The Experiment:}

Decide in 12 cases whether to trade $50 \%$ or $100 \%$ of the generating power of an offshore wind park according to an available forecast given the possibility of a high-speed shutdown, where the wind park stops generating due to excessive wind conditions.

\section{Definition of a "high-speed shutdown" (HSSD) or "cut-off wind" event :}

A high-speed shutdown event occurs typically in the wind range above $21-27 \mathrm{~m} / \mathrm{s}$, mostly known as the cut-off wind threshold of $25 \mathrm{~m} / \mathrm{s}$. Note that wind turbines use both wind gusts and the mean wind to determine, whether or not they turn into high-speed shutdown (HSSD). 


\section{Offshore wind power decision making in extreme events}

\section{Type of forecasts used in the experiment:}

In the experiement are determinisitic and probabilistic forecasts for the day-ahead horizon. All forecasts are generated with input from NWP (numerical weather prediction) forecasts from the OOUTC cycle the day before.

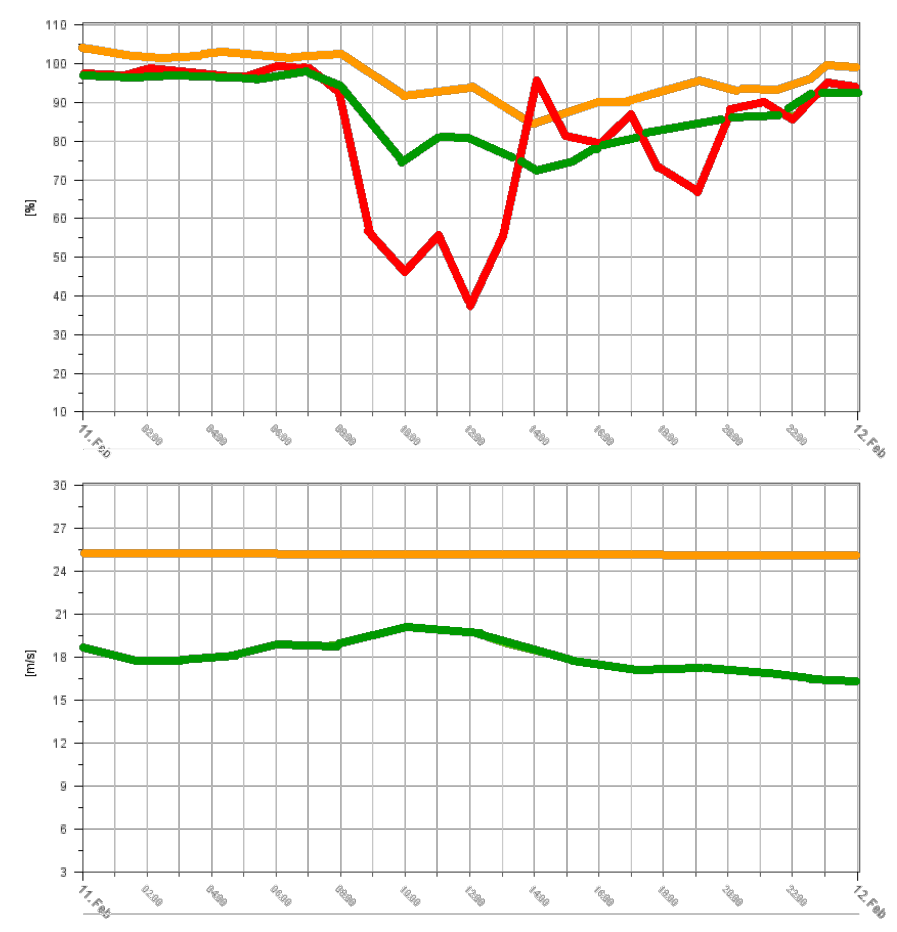

3 independent deterministic wind power forecasts in the unit [\% of installed capacity] based on 3 different NWP (numerical weather prediction) models

1 wind speed forecast in the unit $[\mathrm{m} / \mathrm{s}]$, which is a mean forecast from 75 ensemble members and smoother than a typical deterministic forecast. Additionally, you see a reference line for the $\mathbf{2 5 m} / \mathrm{s}$ threshold reference value for high-speed shutdown or also sometimes called cut-off wind speed threshold. 


\section{Offshore wind power decision making in extreme events}

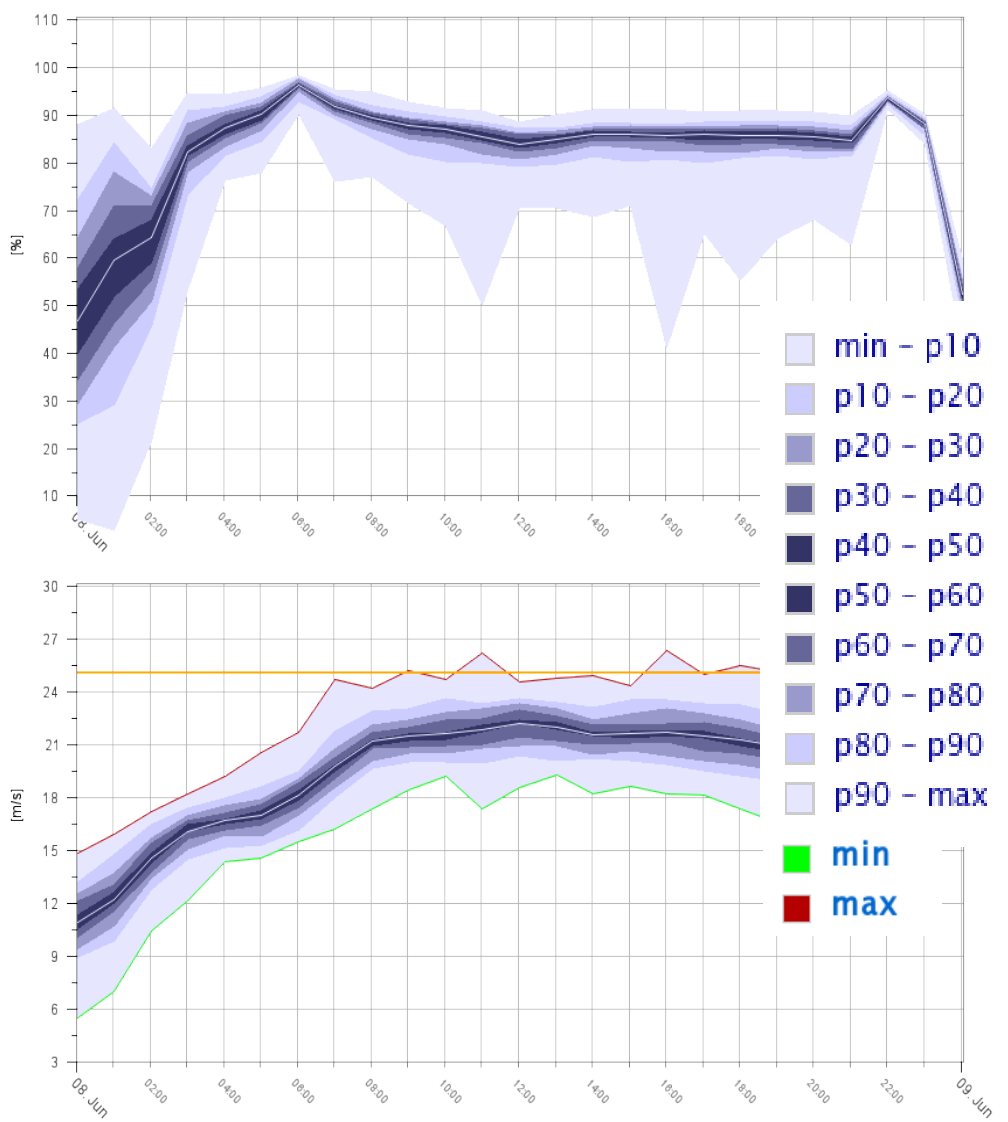

9 wind power percentiles (P10..P90) and a mean (white line) in the unit [\% of installed capacity] generated from 75 NWP forecasts of a multi-scheme ensemble prediction system.

\section{9 wind speed percentiles P10..P90 and a} mean (white line) in the unit [\% of installed capacity] generated from 75 NWP forecasts of a multi-scheme ensemble prediction system.

Note: The percentiles here are physically based uncertainty bands and provide an overview of the uncertainty of the forecast.

Definition: A percentile indicats the value below which a given percentage of foreasts from the 75 available forecasts falls.

E.g., the 20th percentile is the value below which $20 \%$ of the forecasts are found. 


\section{Forecast Game 1:}

\section{Offshore wind power decision making in extreme events}

\section{The cost profile}

To reflect the costs of large and small errors we have defined a simplified cost function for the period, where high-speed shutdown (HSSD) can take place.

Definitions:

- the wind farm is $100 \mathrm{MW}$ and the spot market price is 50 Eur/Mwh.

- balance costs are equivalent to spot market prices

- The cost function will only consider your choice for the hours, where the actual generation is full load or no generation

\begin{tabular}{l|ll} 
Trading & HSSD $^{*}$ & No HSSD* \\
\hline $100 \%$ & -5.000 & 5.000 \\
$50 \%$ & 0 & 2.500 \\
* High-Speed Shutdown == cut-off winds
\end{tabular}

Note that trading $\mathbf{1 0 0} \%$ is a risky choice that can both increase your income and loss.

The more conservative $50 \%$ trading strategy eliminates the risk of a loss, because balance costs are equal to spot market prices and you can curtail the wind farm to avoid balance costs. 


\section{ANALYSIS of Ouestions - preferred information -}

Histogram of participants' preferred information

No one preferred to make decisions based on deterministic power forecast alone.

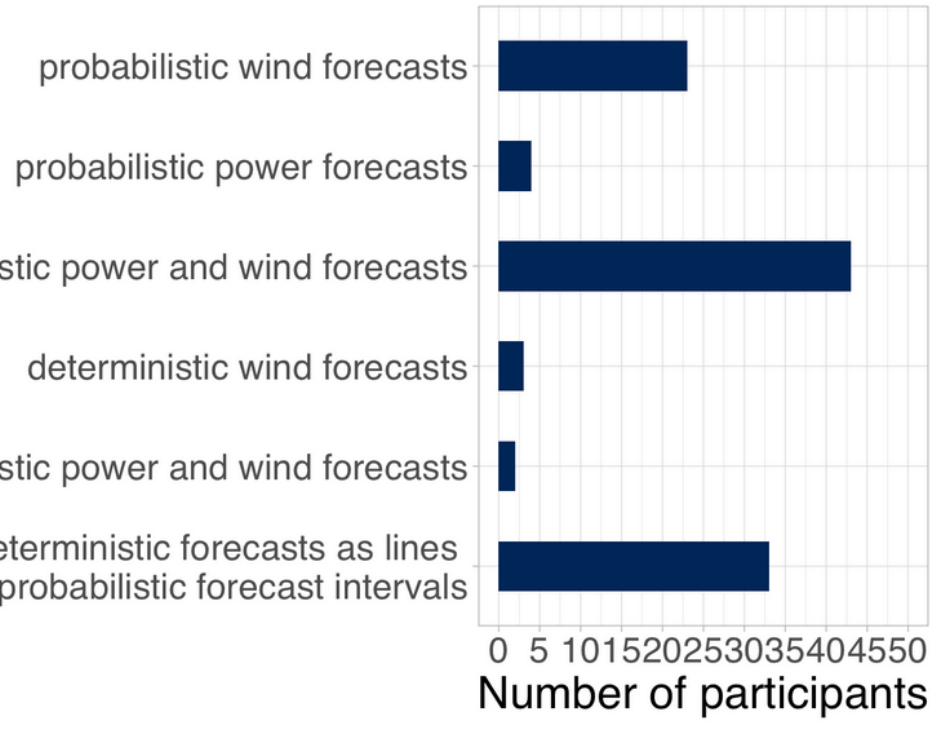




\section{Offshore wind power decision making in extreme events} ANALYSIS - final balance -

108 participants:

Best score deterministic: 25.000 EUR Best score nrobabilistic: 27.500 EUR

Histogram of participants' final balance based on deterministic vs. probabilistic forecasts
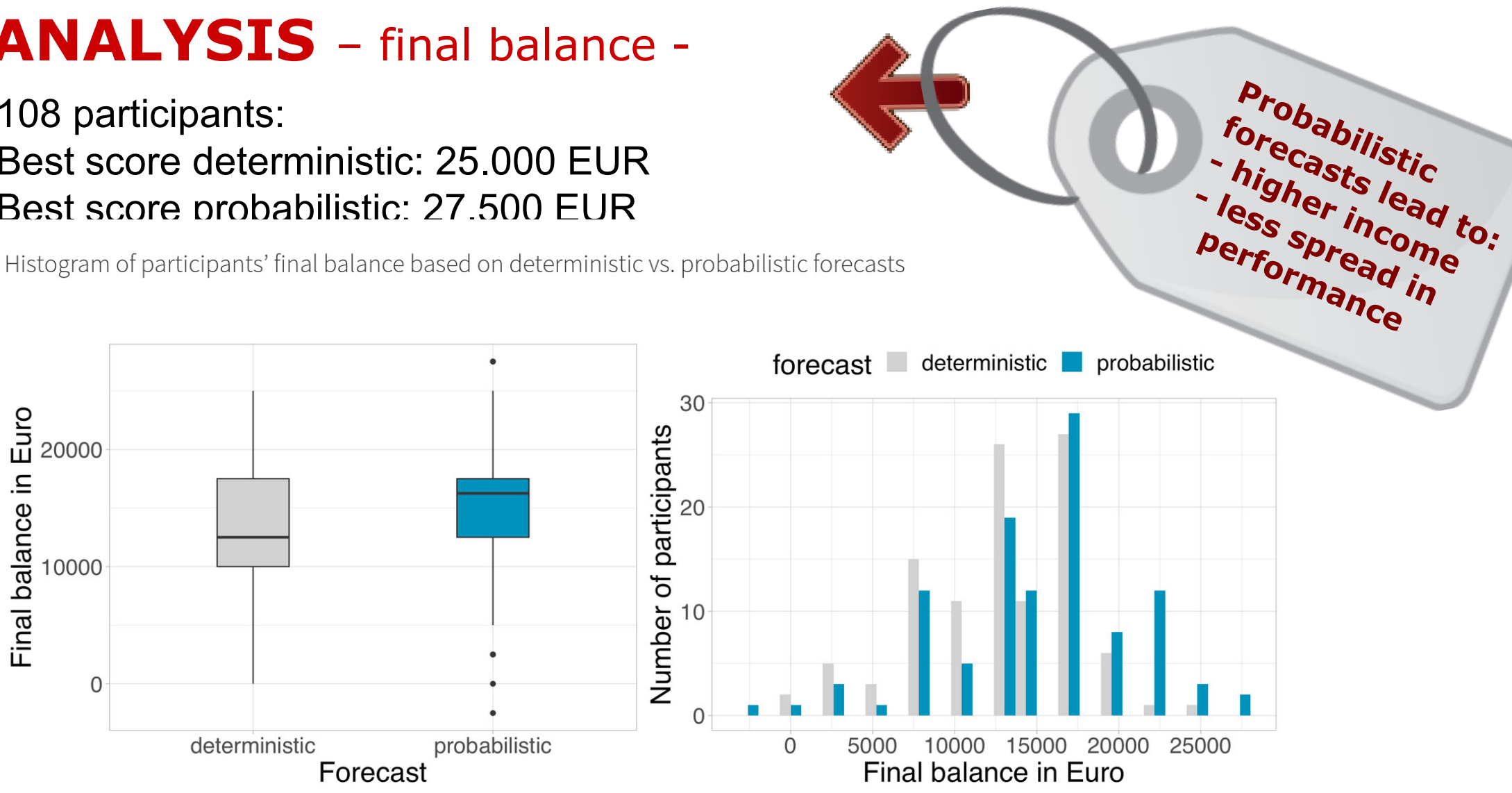


\section{WP3.3: Meteorological Measurements and Instrumentation}

\section{Standardization for Integration into Grid Codes}

\section{Results from 2 Workshops: ICEM 2019 \& WIW 2019}

\section{Need for Industry Standard ?}

$\rightarrow$ Need for best practices: BUT too strict standards are worse than non

$\rightarrow$ No standards leads to chaotic data management

$\rightarrow$ Instrumentation without maintenance: data looses value

$\rightarrow$ Maintenance schedules: once, twice per year?

$\rightarrow$ Met instrumentation should be part of the turbine delivery/installation

\section{- Dissemination}

- No consensus on how to accomplish

- ENSO-E is a potential body for dissemination

- Forecasting still undervalued. Need more forecasters in TSOs.

o Need simple advice to give operators, especially in the developing world
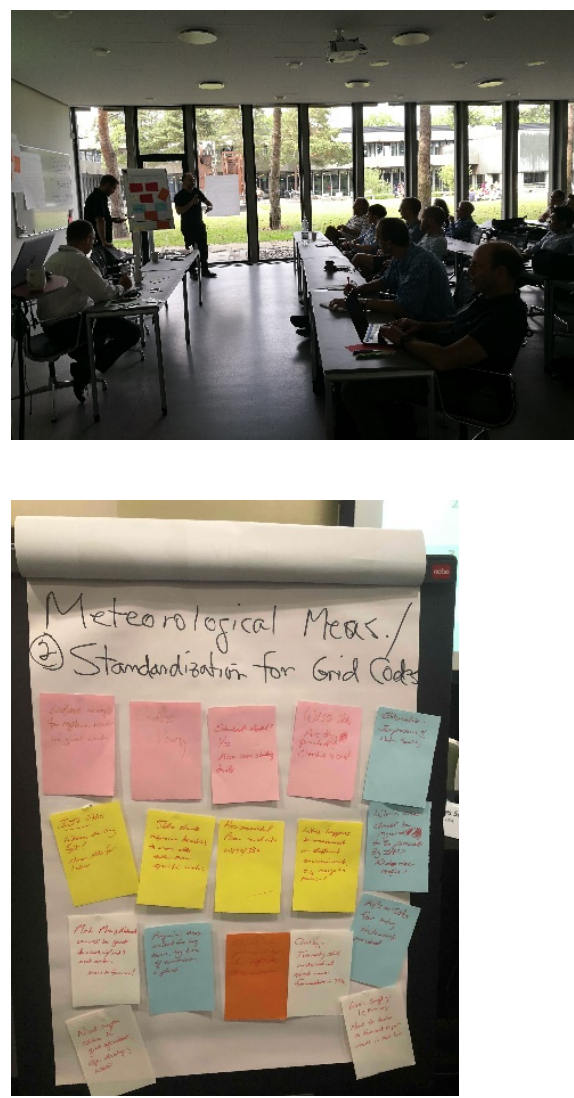


\section{WP3.3: Meteorological Measurements and Instrumentation Standardization for Integration into Grid Codes}

\section{Results from 2 Workshops: ICEM 2019 \& WIW 2019}

- General Agreement that Standards/RPs are Needed

o Grid codes vary from region to region

- Concern about adopting WMO or similar standards, which may be expensive overkill for grid code purposes

o Should reference traceability to standards but be instrument agnostic

○ Could suggest required measurements by IPPs at time of commissioning

- Need education on importance of data quality

- Need to address site selection for instrumentation

o Need to tailor reporting interval to forecast model input needs

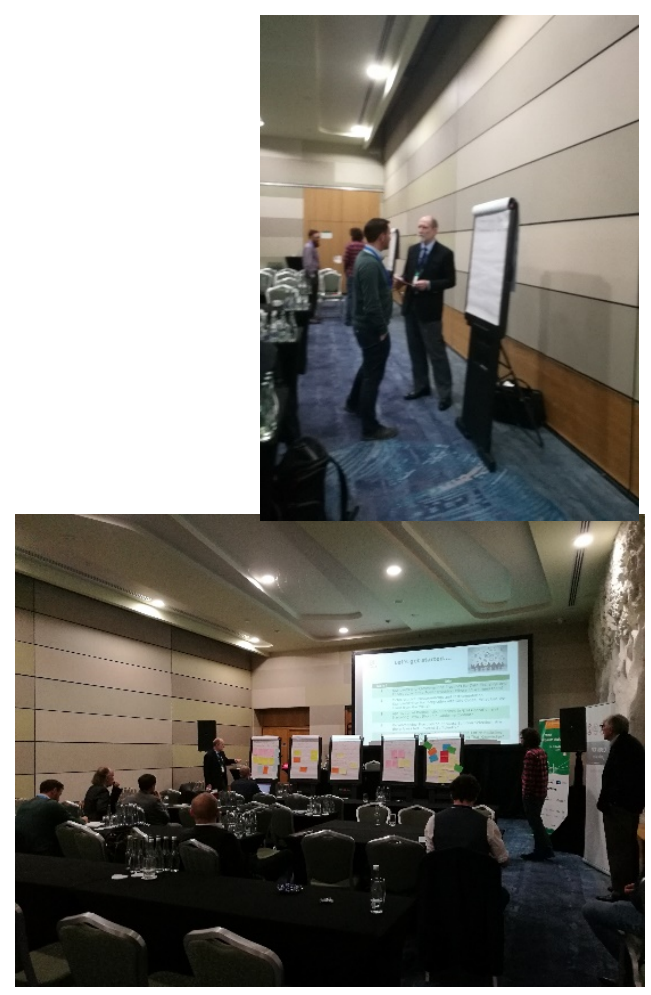




\section{Task 36 Web Presence}

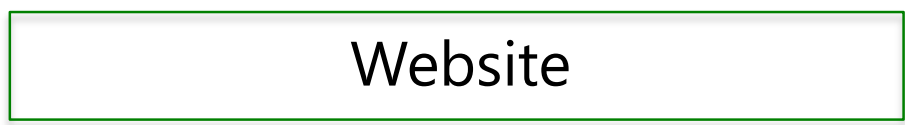

www.ieawindforecasting.dk

\section{IEA WIND TASK 36}

\section{RELATED PROJECTS}

? IEA Wind

2) IEA Wind Task 25- Large-sc.

I IEA Wind Task 31 Wakebench

2 EWeLine

, WFP2

New European Wind Atas

other projects

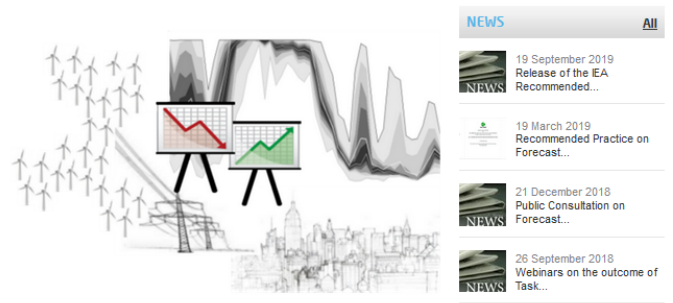

Source: Corinna Mörren, WEPROG

Wind power forecasts have been used operatively for over 20 years.
Despite this fatt, there are stitl several possibilitites to improvere the
torecasts

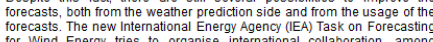

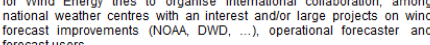

The Task is divided in three work packages: Firstly, acollaboration on the improvement of the scientinc basis for the wind predictions them seveves
This includes numerical weather prediction model physics, but also widel

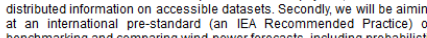

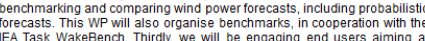

\section{- YouTube Channel}

https://www.youtube.com/channel/UCsP1rL outSXPOECZKicczXg

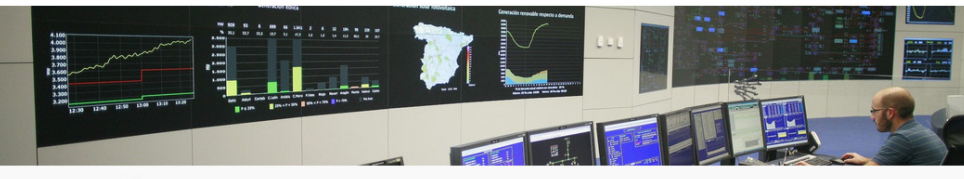

IEA Wind Forecasting ÜBERSICHT

Uploads > aLLEWIEDERGEBE

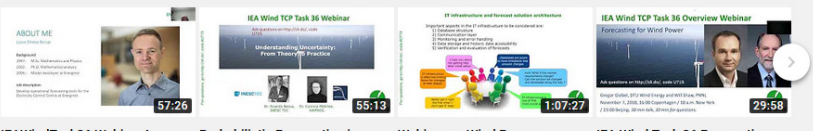
IEAWind Task36 Webinar4 Probabllistic Forecasting in webinar on Wind Power
2018 75 witute 


\section{Handouts}

- 2-page handouts: quick overview of major results

- 3 currently available; can be obtained from:

http://www.ieawindforecasting.dk/publications/po sters-og-handouts

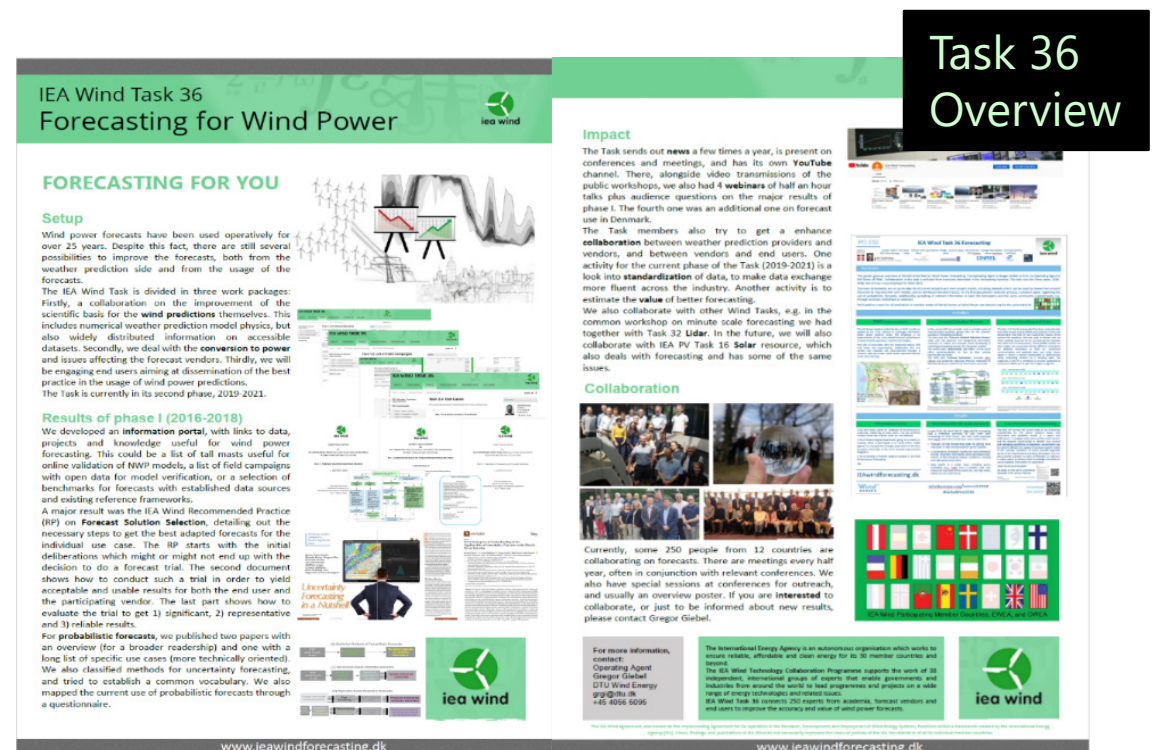

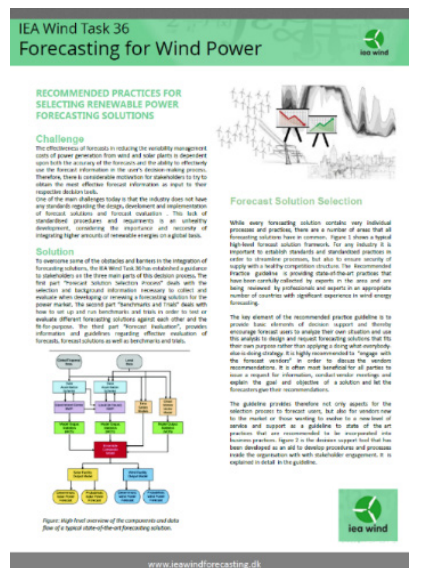
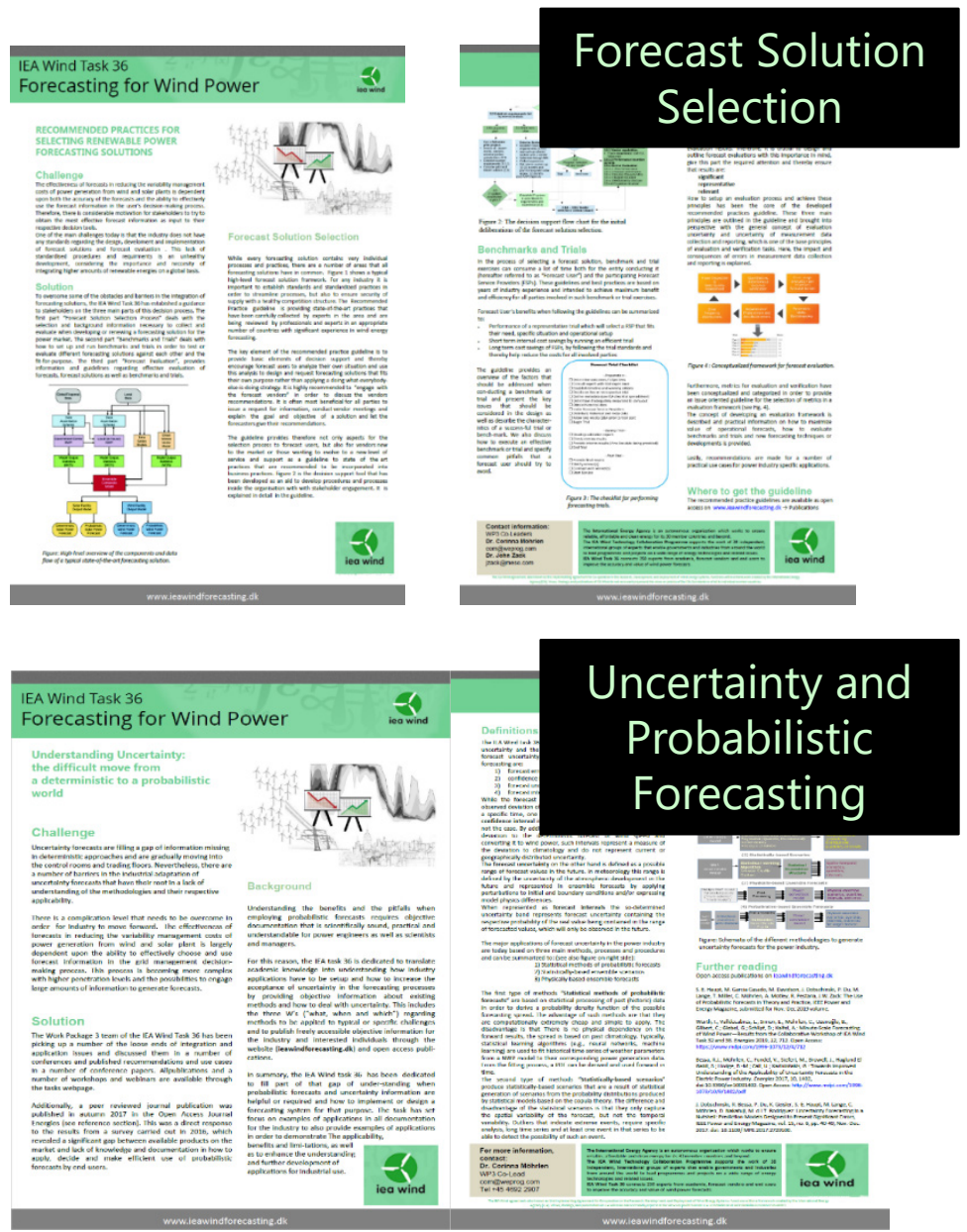


\section{Thank you!}

\section{Gregor Giebel}

Frederiksborgvej 399, 4000 Roskilde, DK grgi@dtu.dk
Will Shaw, PNNL,

Richland (WA), USA

will.shaw@pnnl.gov

The IEA Wind TCP agreement, also known as the Implementing Agreement for Co-operation in the Research, Development, and Deployment of Wind Energy Systems, functions within a framework created by the International Energy Agency (IEA). Views, findings, and publications of IEA Wind do not necessarily represent the views or policies of the IEA Secretariat or of all its individual member countries. 


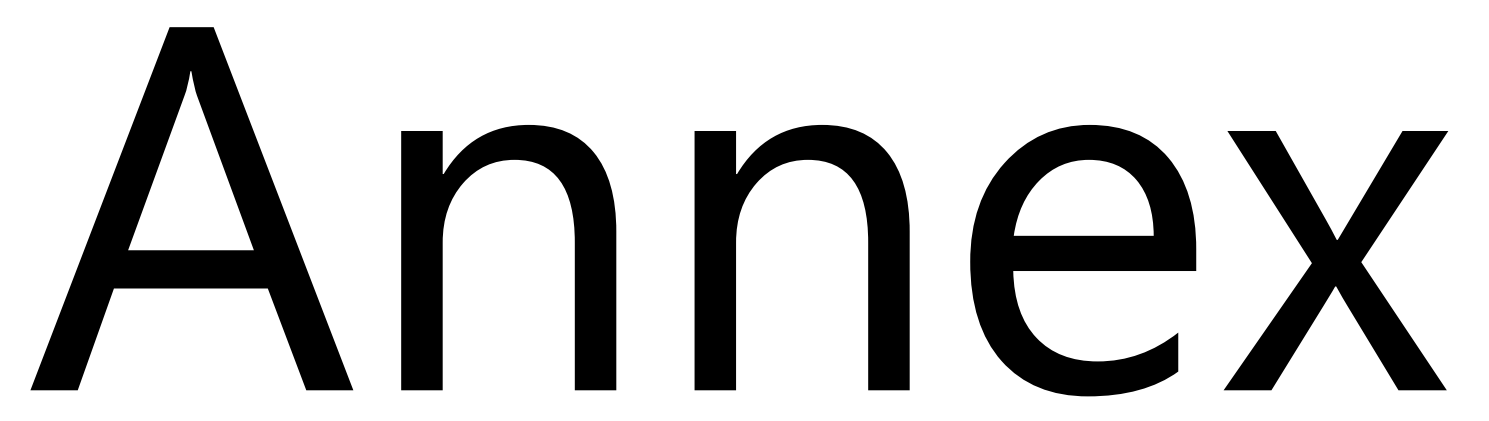




\section{International Energy Agency History}

The IEA was founded in 1974 to help countries co-ordinate a collective response to major disruptions in the supply of oil.

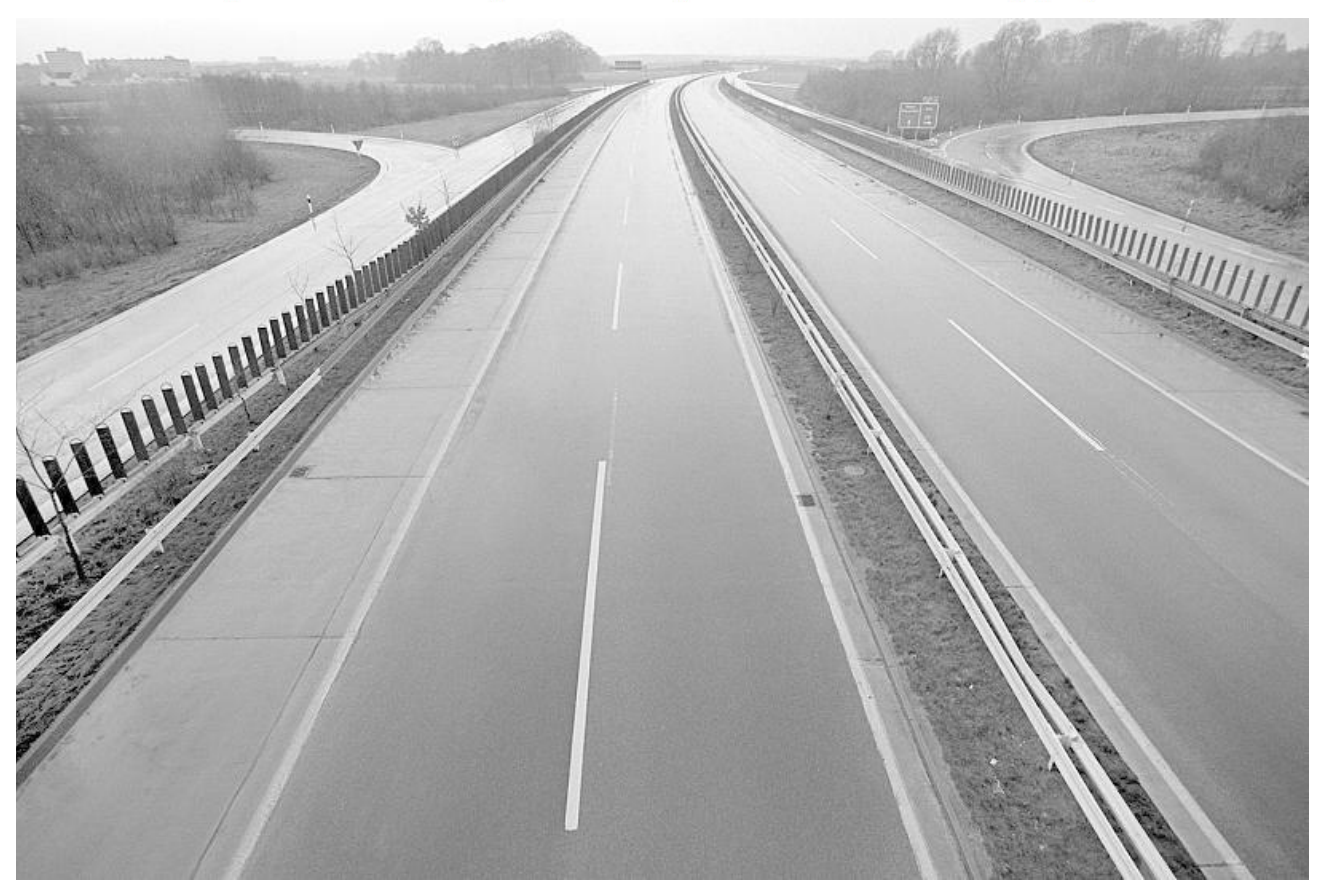

Image source: dpa
Specific Technology Collaboration Programs: Bioenergy TCP Concentrated Solar Power (SolarPACES TCP) Geothermal TCP Hydrogen TCP Hydropower TCP Ocean Energy Systems (OES TCP)

Photovoltaic Power Systems (PVPS TCP) Solar Heating and Cooling (SHC TCP) Wind Energy Systems (Wind TCP) 


\section{iea wind}

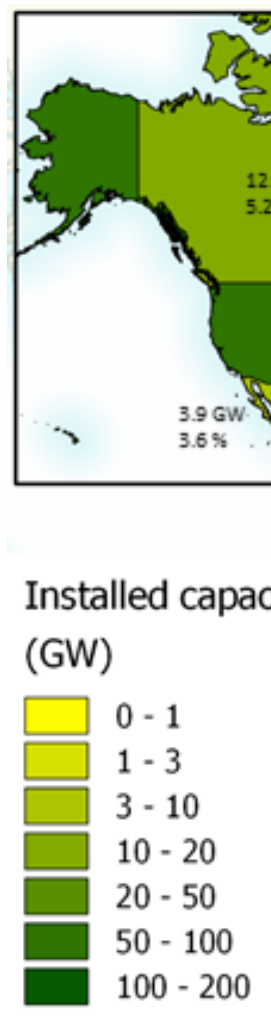

IEA Wind countries

Installed capacity $457 \mathrm{GW}$

Wind share $6.1 \%$
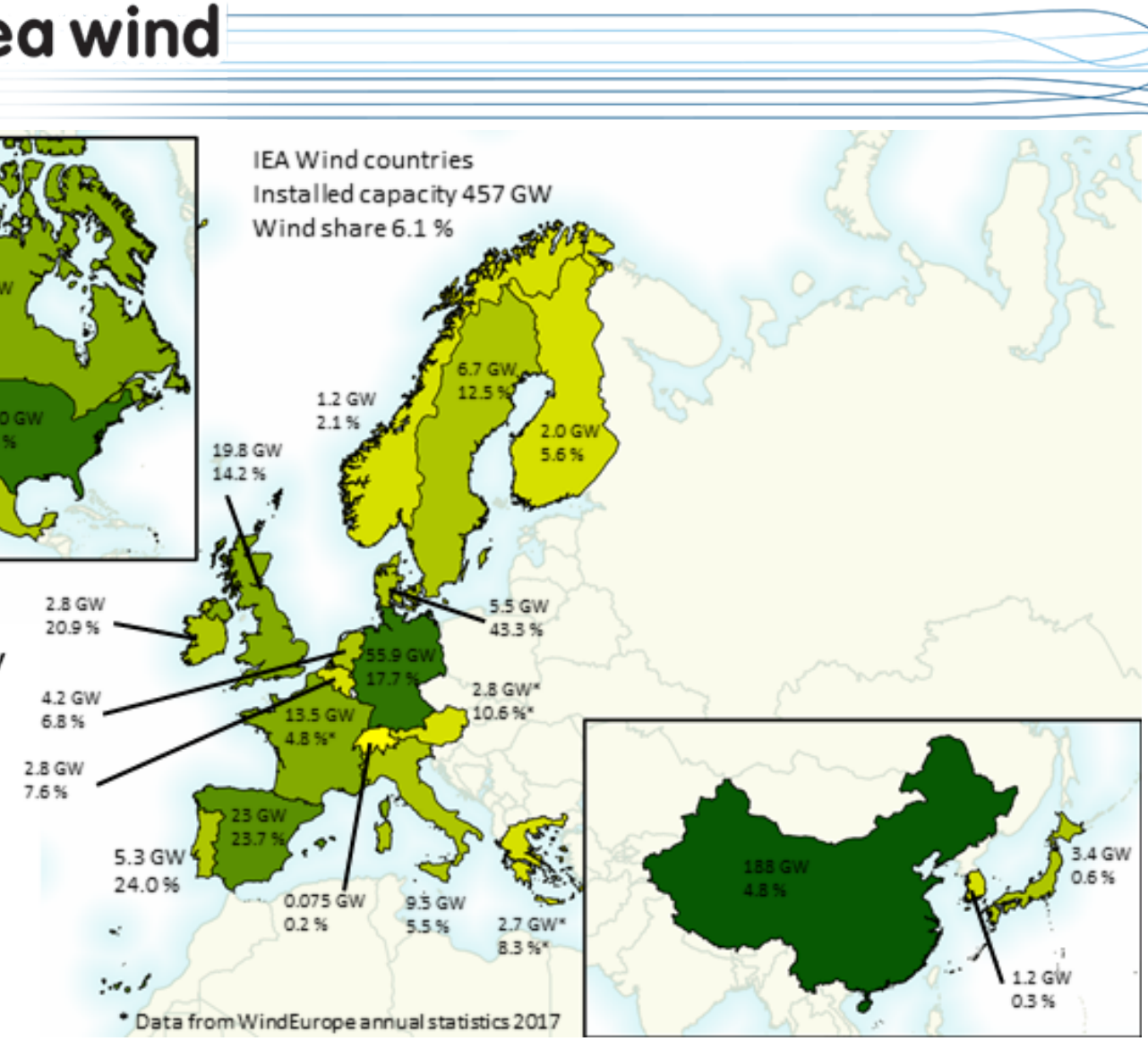

Task 36 members: AT, CN, DE, DK, ES, FI, FR, IE, PT, SE, UK, US

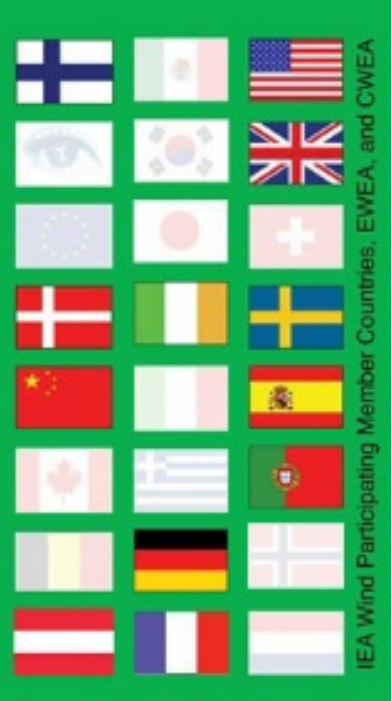


Task 11 Base Technology Exchange Task 19 Wind Energy in Cold Climates Task 29 Mexnext III: Analysis of Wind Tunnel Measurements and Improvements of Aerodynamic Models Task 30 Offshore Code Comparison Collaboration, Continued, with Correlation (OC5)

Task 39 Quiet Wind Turbine Technology Task 40 Downwind Turbines Task 41 Distributed Energy Task 42 Wind Turbine Lifetime Extension

\section{See ieawind.org!}

Task 31 WAKEBENCH: Benchmarking Wind Farm Flow Models

Task 32 LIDAR: Wind Lidar Systems for Wind Energy Deployment

Task 36 Forecasting for Wind Energy

Task 25 Design and Operation of Power Systems with Large Amounts of Wind Power Task 27 Small Wind Turbines in High Turbulence Sites

Task 37 Wind Energy Systems Engineering Task 26 Cost of Wind Energy

Task 28 Social Acceptance of Wind Energy Project

Task 34 Working Together to Resolve the Environmental Effects of Wind Energy (WREN) 
Short-term prediction of wind power, quickly explained 


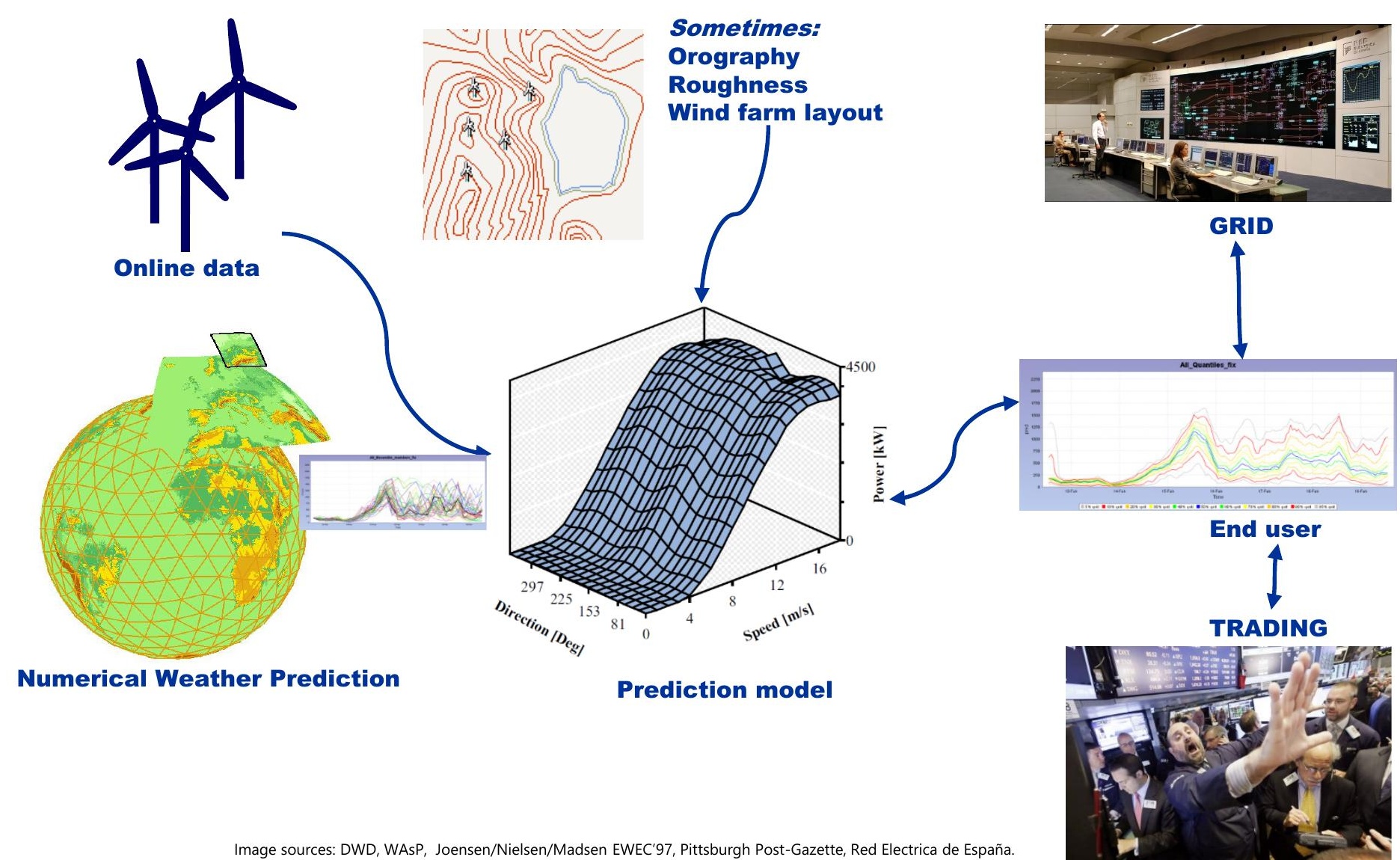




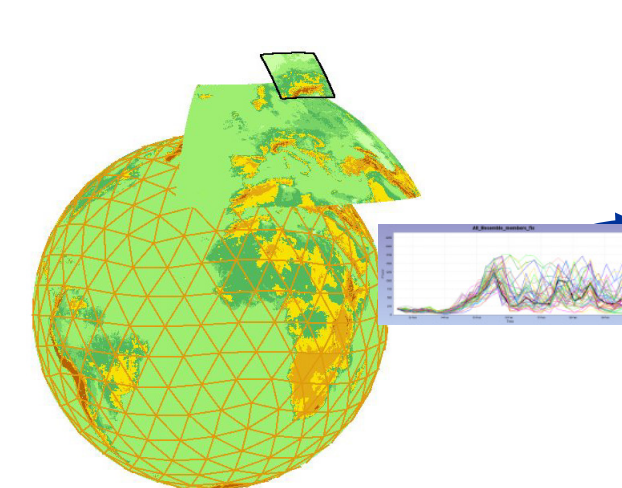

Numerical Weather Prediction

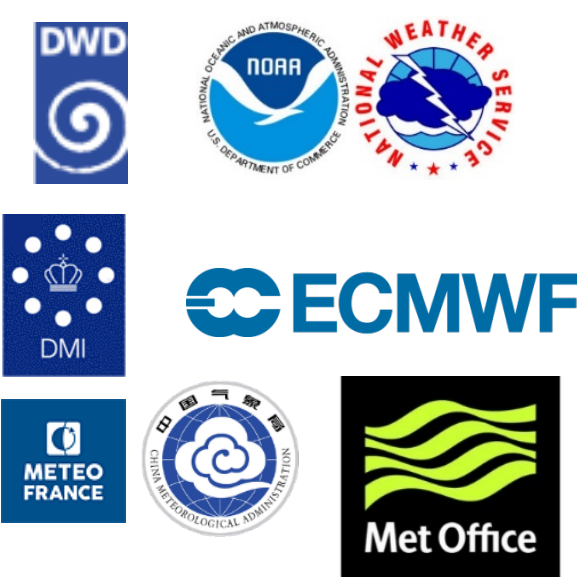

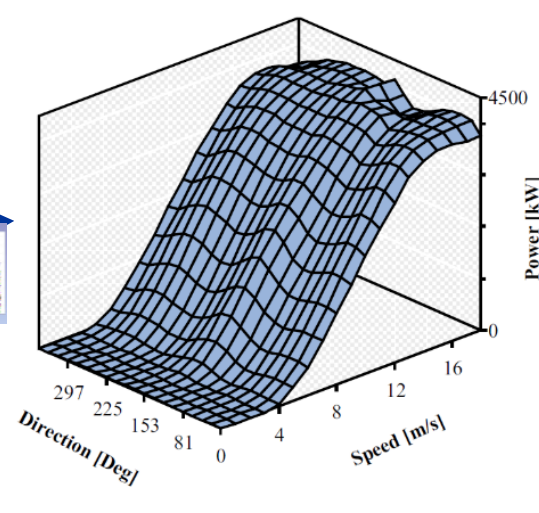

Prediction model

\section{$\mathrm{ENFOR} \approx$}

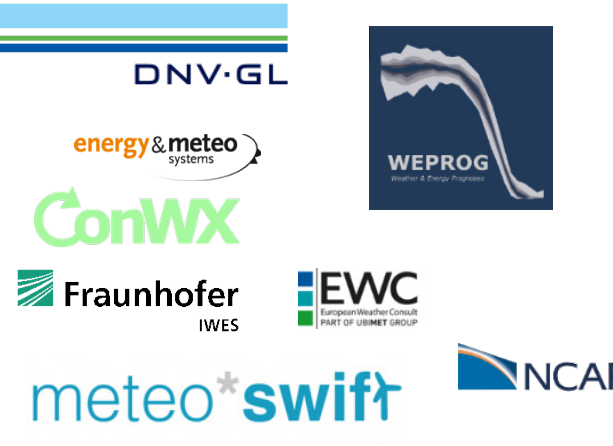

VAISALA Gcast

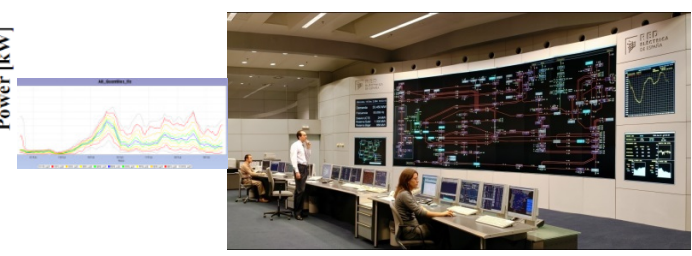

End user

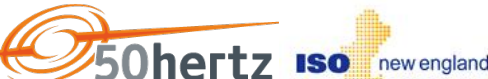

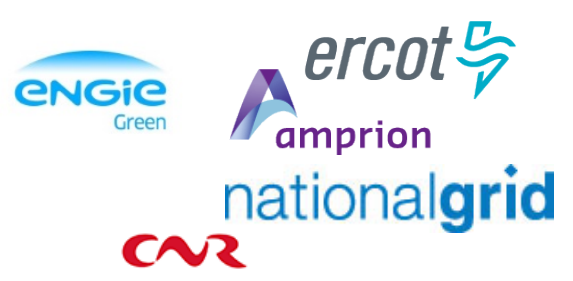

California ISO VATTENFALL \# e.on Thennet ENERGINET/DK Statoil 


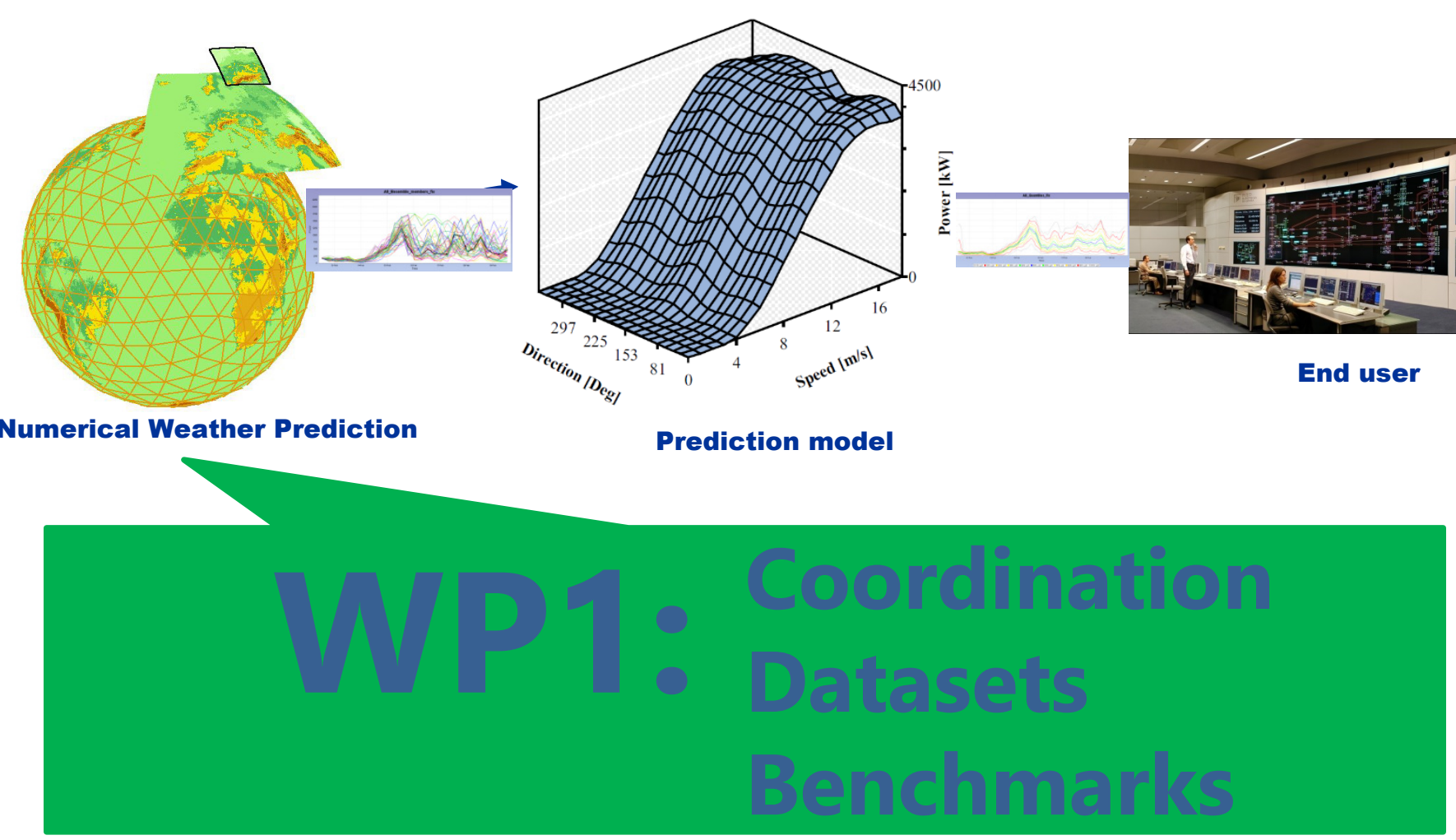




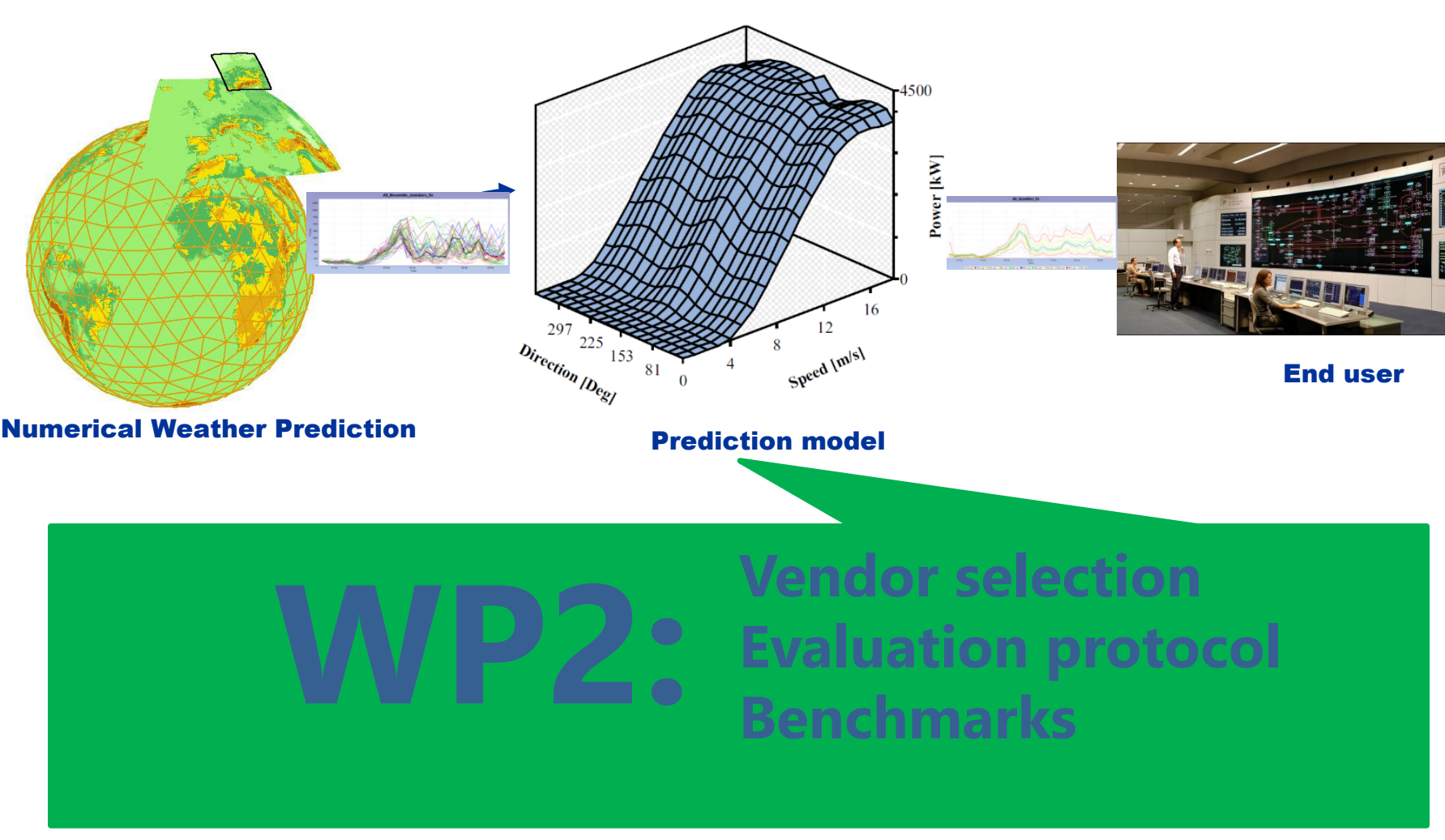




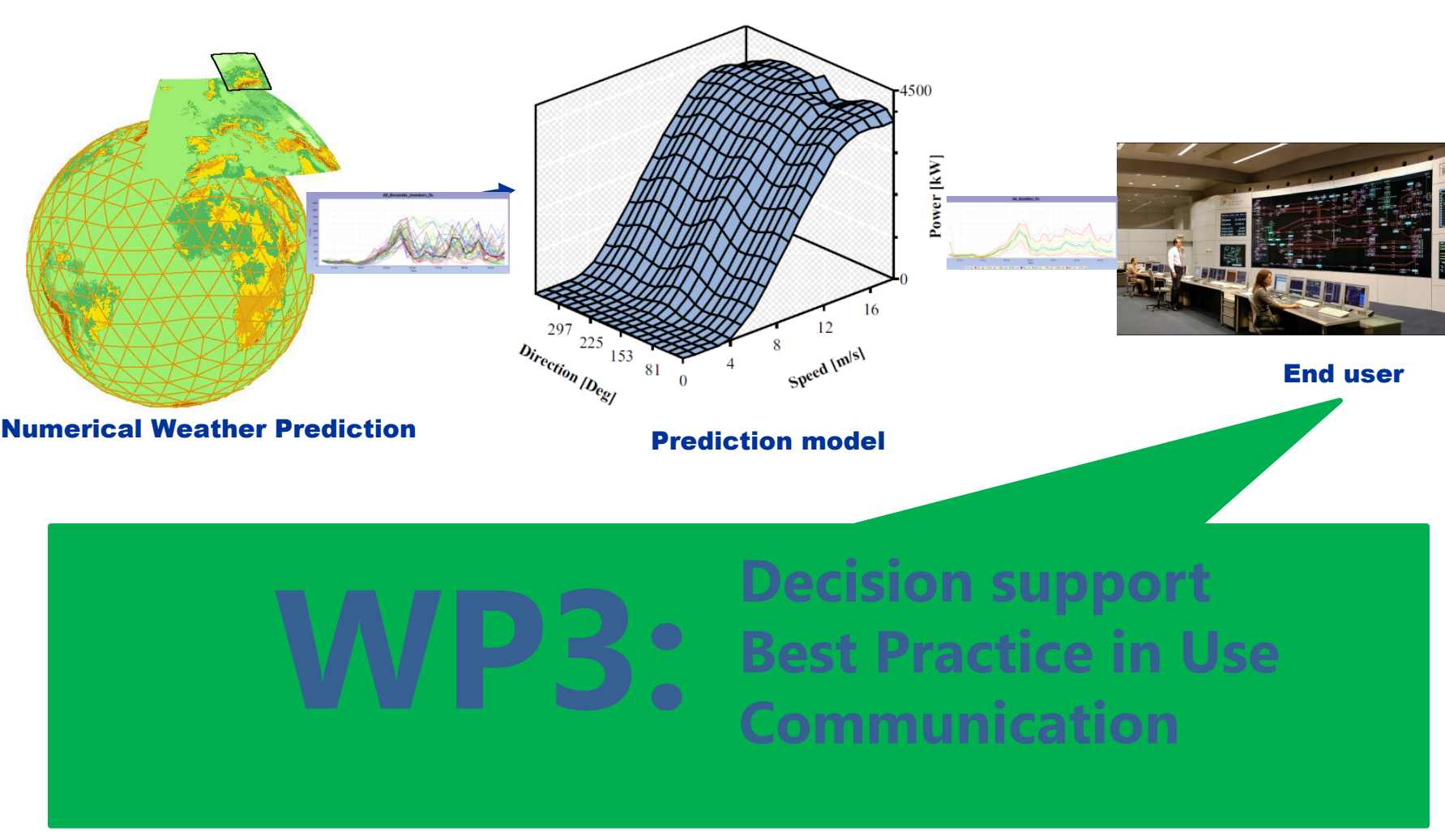




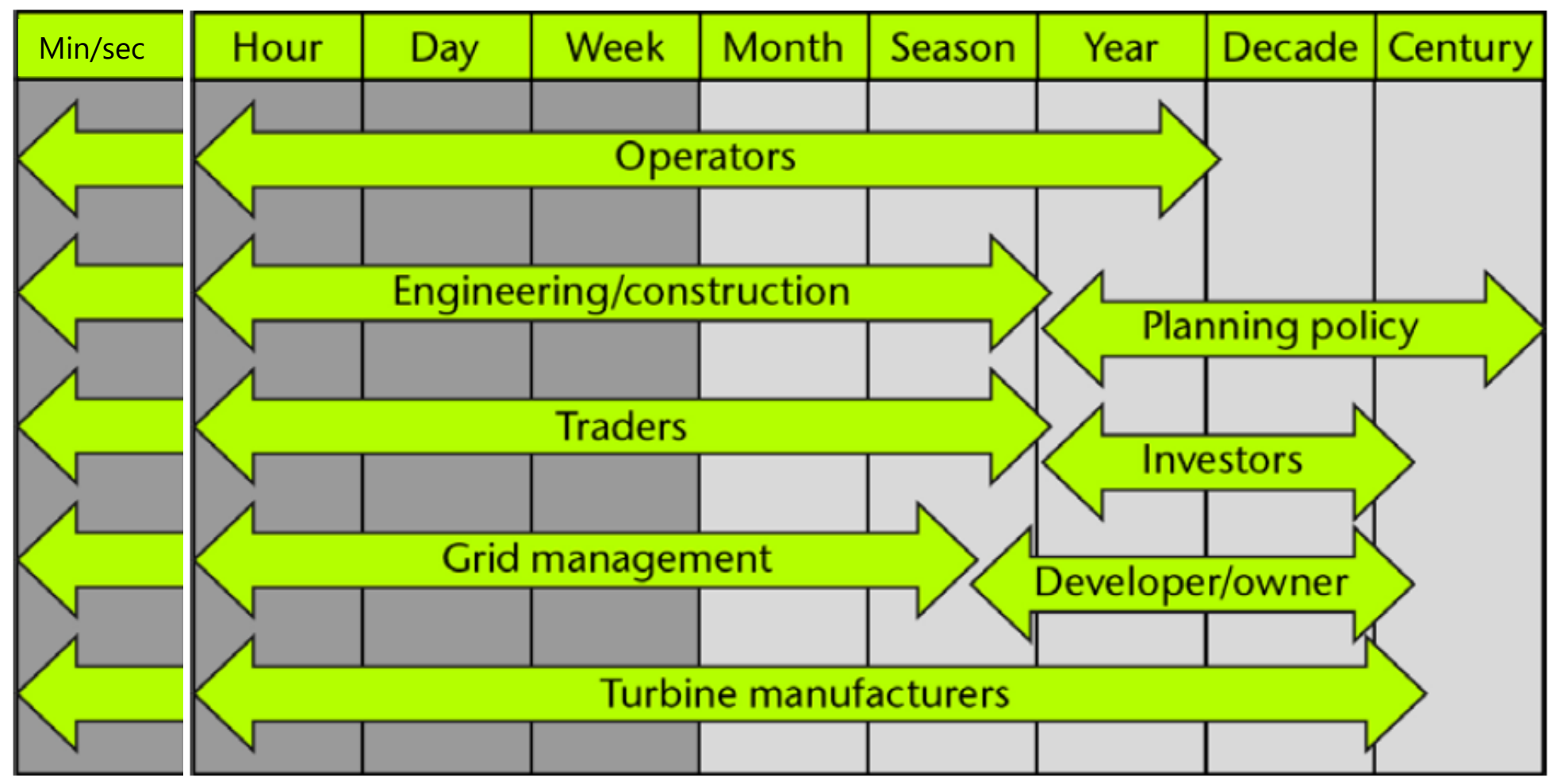

Figure 1: Timescales for the future of wind

(c) Crown copyright Met Office 


\section{Task 36 Phase 2: Work Package Scope}

\section{- WP 1: Global Coordination in Forecast Model Improvement}

- 1.1 Compile list of available wind data sets suitable for model evaluation

- 1.2 Annually document field measurement programs \& availability of data

- 1.3 Verify and validate NWP improvements with common data sets

- 1.4 Work with the NWP centers to include energy forecast metrics in evaluation of model upgrades

- WP 2: Power and Uncertainty Forecasting

- 2.1 Update the IEA Recommended Practice on Forecast Solution Selection

- 2.2 Uncover uncertainty origins \& development through the whole modelling chain

- 2.3 Set-up and disseminate benchmark test cases and data sets

- 2.4 Collaborate with IEC on standardisation for forecast vendor-user interaction

- WP 3: Optimal Use of Forecasting Solutions

- 3.1 Use of forecast uncertainties in the business practices

- 3.2 Review existing/propose new best practices to quantify value of probabilistic forecasts.

○ 3.3 Develop data requirements for real-time forecasting models for use in grid codes 


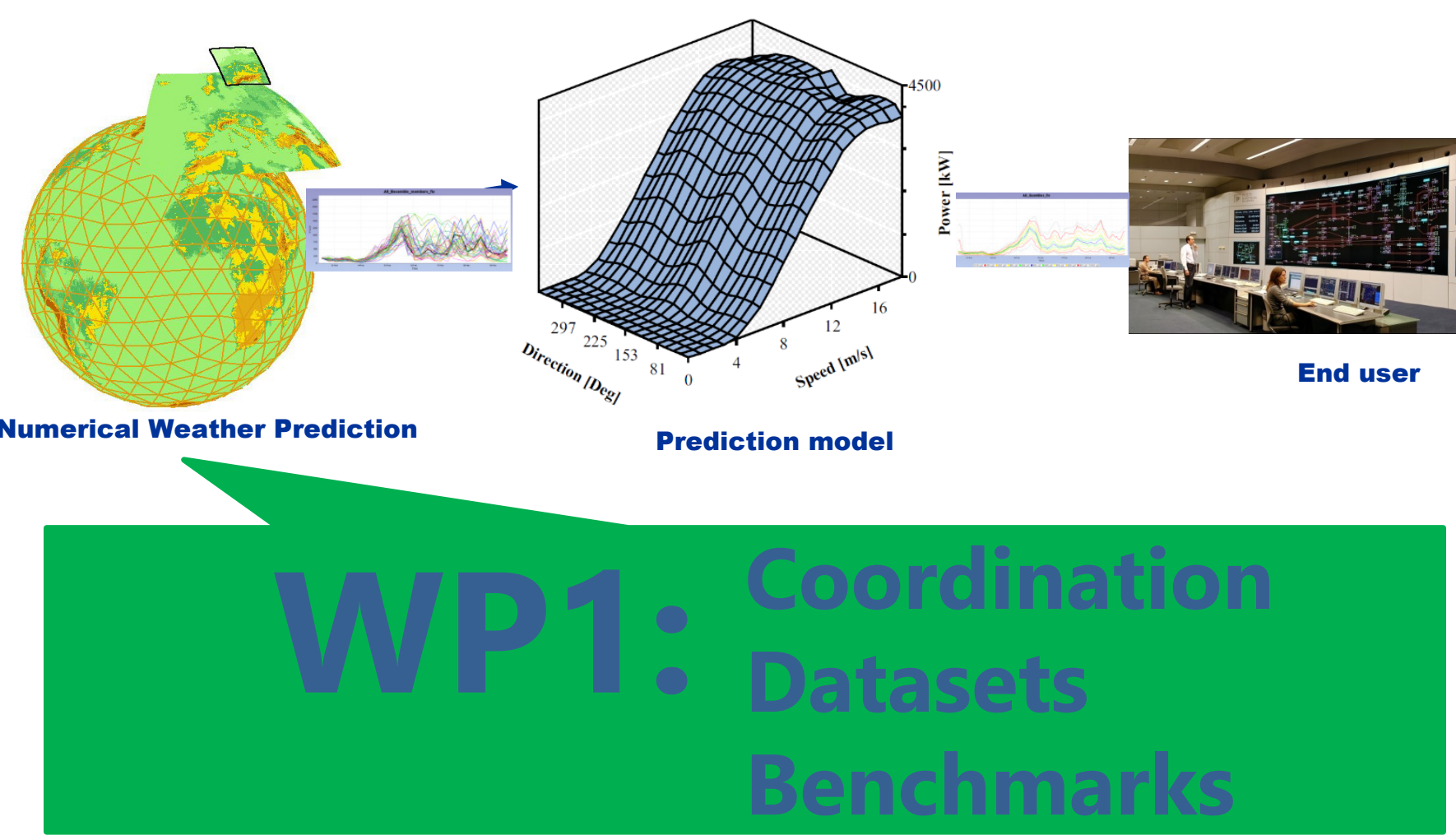




\section{WP1 Meteorology}

\section{Lead:}

- Helmut Frank, DWD

- Will Shaw, PNNL

Mission:

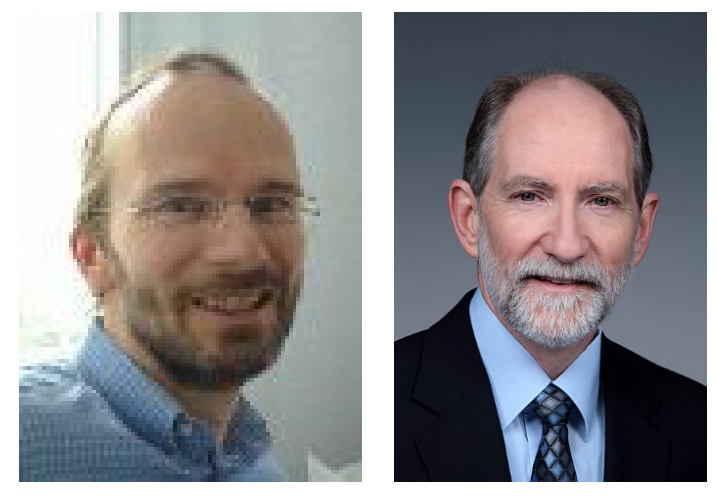

To coordinate NWP development for wind speed \& power forecasting 


\section{WP1 Meteorology}

- Task 1.1: Compile list of available data sets, especially from tall towers.

- Task 1.2: Creation of annual reports documenting and announcing field measurement programs and availability of data.

- Task 1.3: Verify and Validate the improvements through a common data set to test model results upon and discuss at IEA Task meetings 


\section{WP1 Meteorology Current state}

- V\&V benchmark defined (US results to be published end of June, benchmark to be published on A2E site)

- Continuously updating the list, and work underway to use the collected data sets for Numerical Weather Prediction

\begin{tabular}{|c|c|c|c|c|c|c|c|c|c|}
\hline SITE NAME & COORDINATES & $\begin{array}{l}\text { ALTITUDE } \\
\text { ABOVE } \\
\text { MSL }\end{array}$ & $\begin{array}{l}\text { TOWER } \\
\text { HEIGHT }\end{array}$ & URL & CONTACT & DATA POLICY & $\begin{array}{l}\text { DATA } \\
\text { FORMAT }\end{array}$ & $\begin{array}{l}\text { OBS. } \\
\text { PERIOD }\end{array}$ & OTHER \\
\hline Cabauw, NL & $\begin{array}{l}4.926^{\circ} \mathrm{E} \\
51.97^{\circ} \mathrm{N}\end{array}$ & $-0.7 \mathrm{~m}$ & $200 \mathrm{~m}$ & www.cesar-observatory.nlindex.php & henk.klein.baltink@knmi.nl & Cesar data policy & netCDF & $\begin{array}{l}2000-04-01 \\
\text { to previous } \\
\text { month }\end{array}$ & \\
\hline $\begin{array}{l}\text { IJmuiden, } \\
\text { NL }\end{array}$ & $\begin{array}{l}3.436^{\circ} \mathrm{N} \\
52.848^{\circ} \mathrm{E}\end{array}$ & $0 \mathrm{~m}$ & $92 \mathrm{~m}$ & $\begin{array}{l}\text { wnw.meteomastimuiden.nl/en } \\
\text { Imeasurement-campaign/ }\end{array}$ & verhoef@ecn.nl & & & since 2012 & $\begin{array}{l}\text { offshore North } \\
\text { Sea }\end{array}$ \\
\hline Risø, DK & $\begin{array}{l}12.088^{\circ} \mathrm{E}, \\
55.694^{\circ} \mathrm{N}\end{array}$ & $0 \mathrm{~m}$ & $125 \mathrm{~m}$ & $\begin{array}{l}\frac{\text { rodeo.dtu.dkfrodeo }}{\text { Projectoverview.aspx?\&Project=5\& }} \\
\text { Rnd }=975820\end{array}$ & Allan Vesth & Ask nicely & & ${ }^{1995-11-20}$ & $\begin{array}{l}\text { Data measured } \\
\text { since 1958; } \\
\text { some months } \\
\text { break in } 2008 \text {. }\end{array}$ \\
\hline Østerild, DK & $\begin{array}{l}8.88080^{\circ} \mathrm{E} \\
57.04888^{\circ} \mathrm{N}\end{array}$ & $9 \mathrm{~m}$ & $250 \mathrm{~m}$ & $\begin{array}{l}\frac{\text { rodeo.dtu.dk/rodeo }}{\text { Projectoverview. aspx? \&Project=179\& }} \\
\text { Rnd }=975820\end{array}$ & Yoram Eisenberg & Ask nicely & & $2015-01-28$ & $\begin{array}{l}\text { Two } 250 \mathrm{~m} \\
\text { masts in } 4.3 \mathrm{~km} \\
\text { distance, both } \\
\text { instrumented. } \\
\text { Additionally, } 7 \\
\text { smaller masts }\end{array}$ \\
\hline
\end{tabular}




\section{Minute scale forecasting}

- How to use Lidars, Radars or SCADA for very short term forecasts

- $30 \mathrm{sec}-15 \mathrm{~min}$.

- Workshop with Task 32 Lidars at Risø 12/13 June 2018.

- Slides available from workshop website.

- Complete workshop on YouTube.

- Summary paper in Energies journal.

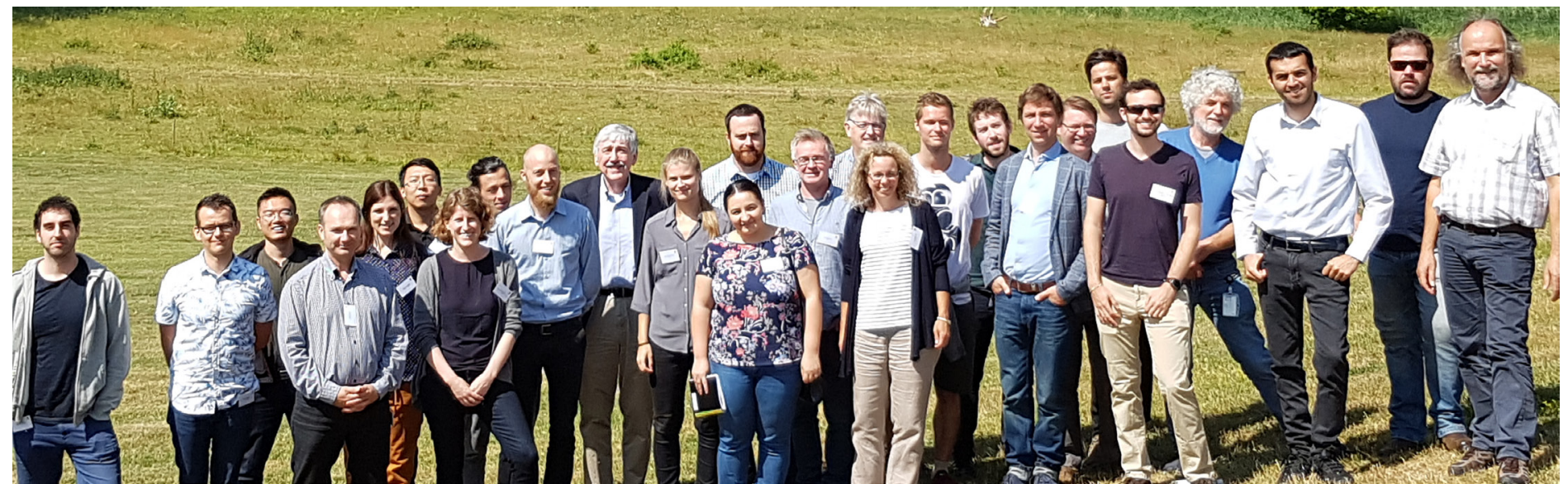




\section{Minute scale forecasting}

- How to use Lidars, Radaı $\equiv$ Youtube iea wind forecasting Q 1 표

- $30 \mathrm{sec}$ - $15 \mathrm{~min}$.

- Workshop with Task 32 L

- Slides available from wo

- Complete workshop on '

- Summary paper in Enerc
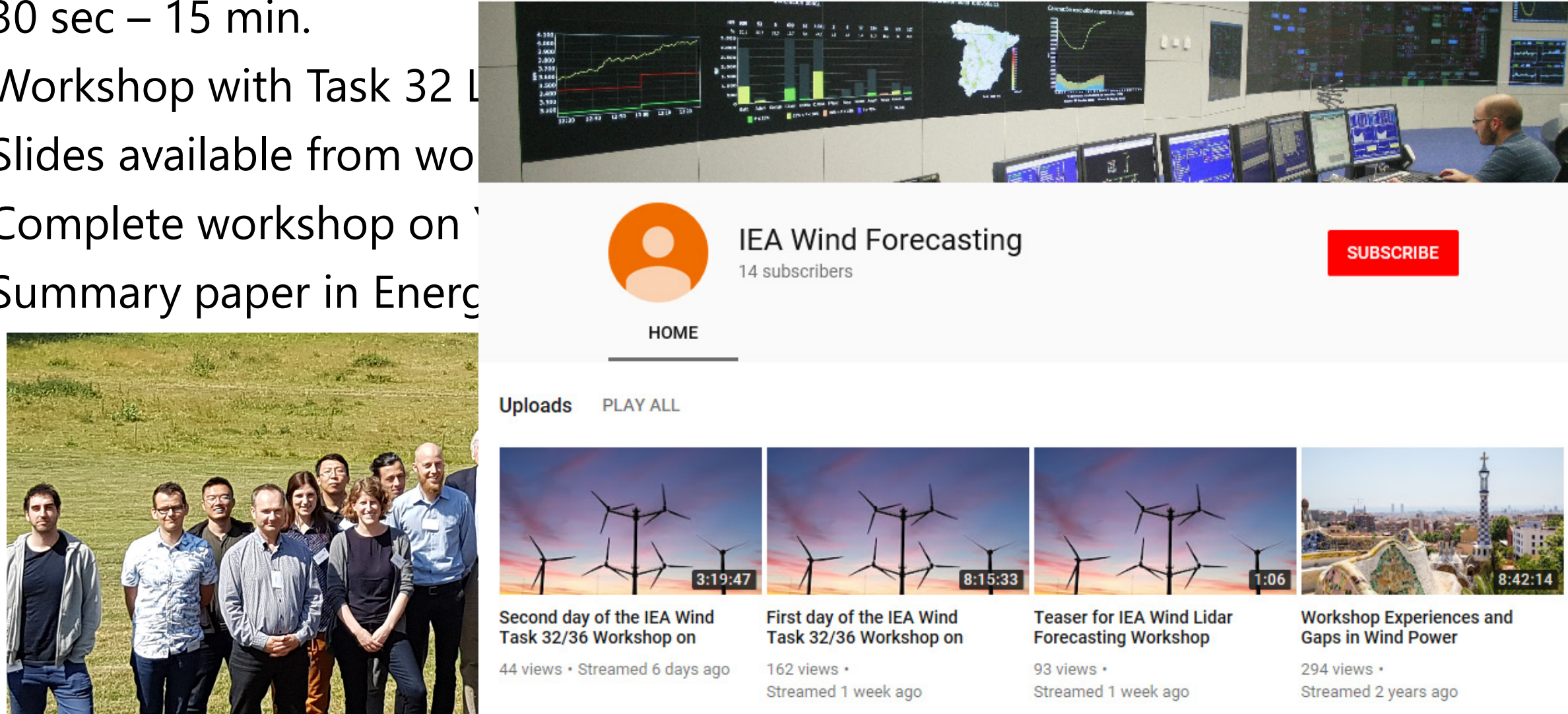

\section{HOME}

Uploads PLAY ALL

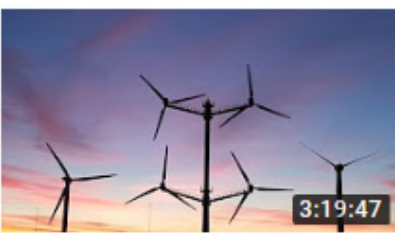

Second day of the IEA Wind Task 32/36 Workshop on

44 views $\cdot$ Streamed 6 days ago

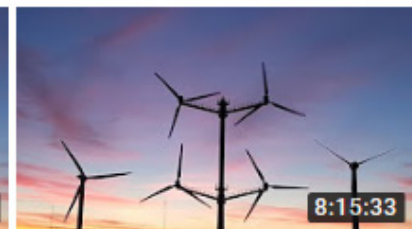

First day of the IEA Wind Task 32/36 Workshop on 162 views

Streamed 1 week ago

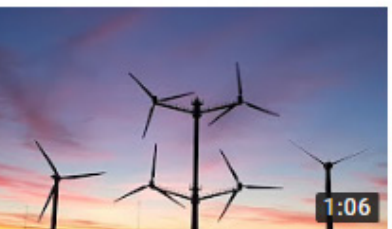

Teaser for IEA Wind Lidar Forecasting Workshop 93 views . Streamed 1 week ago

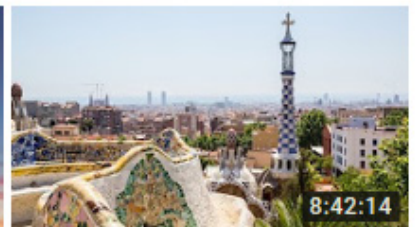

Workshop Experiences and Gaps in Wind Power 294 views.

Streamed 2 years ago 


\section{Minute scale forecasting}

- How to use Lidars, Radars or SCADA for very short 1

Minute-Scale Forecasting of Wind Power-Results from the Collaborative Workshop of IEA Wind Task 32 and 36

- $30 \mathrm{sec}-15 \mathrm{~min}$.

- Workshop with Task 32 Lidars at Risø 12/13 June 20

- Slides available from workshop website.

- Complete workshop on YouTube.

- Summary paper in Energies journal.

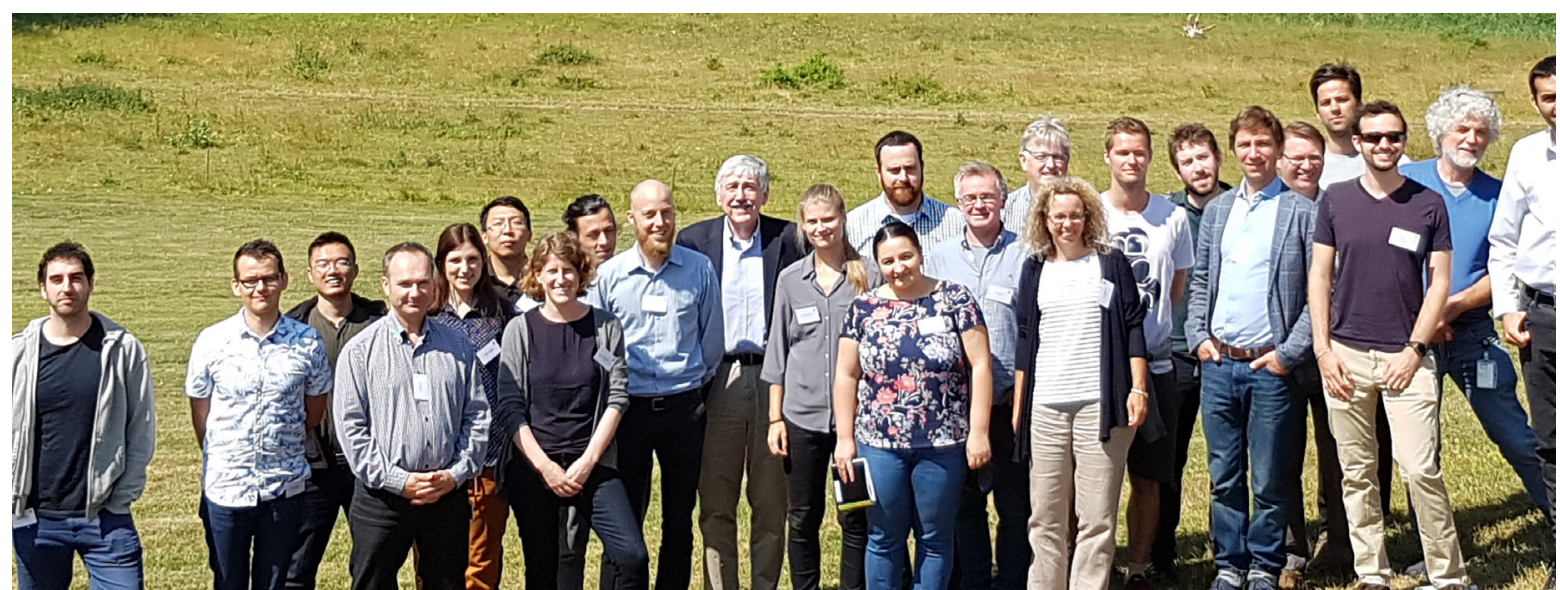

Ines Würth ${ }^{1, *}$, Laura Valldecabres ${ }^{2}$, Elliot Simon ${ }^{3} \oplus$, Corinna Möhrlen ${ }^{4 \oplus,}$,
Ciaran Gilbert $^{7 \oplus}$, Gregor Giebel ${ }^{3} \oplus$, David Schlipf ${ }^{8} \oplus$ and Anton Kaifel ${ }^{9} \oplus$

Stuttgart Wind Energy, University of Stuttgart, Allmandring 5b, 70569 Stuttgart, Germany

ForWind-University of Oldenburg, Institute of Physics, Küpkersweg 70, 26129 Oldenburg, Germany laura.valldecabres@forwind.de

DTU Wind Energy (Rise Campus), Technical Univ

WEPROG, Willemoesade 15, 5610 Asens, De,

crem@ieprogcom Box 534,75121 Uppsala, Sweden; bahriuzunoglu@icomputationalrenewables.com Department of Mathematics, Florida State University, Tallahassee, FL 32310, USA Department of Hectronic and tlectrical Engineering, University of Strathclyde, 204 George S

(1) (943 Flensburg, Germany; david.schlipf@ihs-flensburg. 5063 Stutur Sonnenenergie- und Wasserstoff-Fors

orrespondence: wuerth@ifb.uni-stuttgart.de; Tel.: +49-711-685-68285

Received: 14 December 2018; Accepted: 14 February 2019; Published: 21 February 2019

Abstract: The demand for minute-scale forecasts of wind power is continuously increasing with the growing penetration of renewable energy into the power grid, as grid operators need to ensure
grid stability in the presence of variable power generation. For this reason, IEA Wind Tasks 32 and 36 together organized a workshop on "Very Short-Term Forecasting of Wind Power" in 2018 discuss different approaches for the implementation of minute-scale forecasts into the power industry identify and mitigate barriers to the use of lidars in wind energy applications, while IEA Wind Task 36 focuses on improving the value of wind energy forecasts to the wind energy industry. The workshop identified three applications that need minute-scale forecasts: (1) wind turbine and wind farm control, (2) power grid balancing, (3) energy trading and ancillary services. The forecasting horizons for these applications range from around $1 \mathrm{~s}$ for turbine control to $60 \mathrm{~min}$ for energy market and grid control applications. The methods that can be applied to generate minute-scale forecasts rely on upstream data from remote sensing devices such as scanning lidars or radars, or are based on point measurements from met masts, turbines or profiling remote sensing devices. Upstream data needs to be propagated with advection models and point measurements can either be used in statistical
time series models or assimilated into physical models. All methods have advantages but also shortcomings. The workshop's main conclusions were that there is a need for further investigations into the minute-scale forecasting methods for different use cases, and a cross-disciplinary exchange
of different method experts should be established. Additionally, more efforts should be directed of different method experts should be established. Additionally, more
towards enhancing quality and reliability of the input measurement data.

Keywords: wind energy; minute-scale for numerical weather prediction models 


\section{IEA WIND TASK 36}

\begin{tabular}{l|l|l} 
WP1 Weather Prediction Improvements & WP2 Benchmarks & WP3 Optimal Use of Forecasting Solutions
\end{tabular}

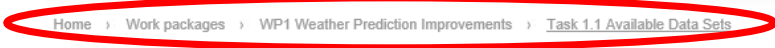

$f$ in

Task 1.1 Available Data Sets

Task 1.1 Available Data Sets

Task 1.2 List of Field Campaigns

Meteorological data from tall towers

Task 1.3 Common Test Data

The following list was compiled by IEA Wind Task 36 Forecasting for Wind Energy

Task 1.4 NWP Forecast Metrics

Another source is The Tall Tower Dataset at INDECIS Data portal. This is database of 222 tall towers around the world compiled with a common format (netCDF) and quality controlled. For some towers the latest data is from 2018 See The Tall Tower Dataset Technical Note for a description of the quality control, and a list of the towers in the appendix.

\begin{tabular}{|c|c|c|c|c|c|c|c|c|c|}
\hline SITE NAME & COORDINATES & $\begin{array}{l}\text { ALTTIUDE } \\
\text { ABOVE } \\
\text { MSL }\end{array}$ & $\begin{array}{l}\text { TOWER } \\
\text { HEIGHT }\end{array}$ & URL & CONTACT & DATA POLICY & $\begin{array}{l}\text { DATA } \\
\text { FORMAT }\end{array}$ & $\begin{array}{l}\text { OBS. } \\
\text { PERIIOD }\end{array}$ & OTHER \\
\hline Cabauw, NL & $\begin{array}{l}4.926^{\circ} \mathrm{E} \\
51.97^{\circ} \mathrm{N}\end{array}$ & $-0.7 \mathrm{~m}$ & $200 \mathrm{~m}$ & www.cesar-observatory.nlifindex.php & marcel.brinkenberg@knmi.nl & Cesar data policy & netCDF & $\begin{array}{l}2000- \\
04-01 \text { to } \\
\text { previous } \\
\text { month }\end{array}$ & \\
\hline IJmuiden, NL & $\begin{array}{l}3.436^{\circ} \mathrm{N} \\
52.848^{\circ} \mathrm{E}\end{array}$ & $0 \mathrm{~m}$ & $92 \mathrm{~m}$ & $\begin{array}{l}\text { mwww windopzee netten/meteomast-imuiden- } \\
\text { mmily }\end{array}$ & $\begin{array}{l}\text { hans.verhoef@tno.nl. } \\
\text { Reqistration for data }\end{array}$ & $\begin{array}{l}\text { Ask here for } \\
\text { permission }\end{array}$ & & $\begin{array}{l}2012- \\
2018\end{array}$ & $\begin{array}{l}\text { Offshore North } \\
\text { Sea }\end{array}$ \\
\hline Risø, DK & $\begin{array}{l}12.088^{\circ} \mathrm{E}_{i} \\
55.694^{\circ} \mathrm{N}\end{array}$ & $0 \mathrm{~m}$ & $125 \mathrm{~m}$ & $\begin{array}{l}\text { rodeo. dtu.dkrodeo/Proiectoverview. aspX? } \\
\text { \&Project=5\&Rnd }=975820\end{array}$ & Allan Vesth & Ask nicely & $x \mid s x$ & $\begin{array}{l}1995- \\
11-20-\end{array}$ & $\begin{array}{l}\text { Data measured } \\
\text { since 1958; } \\
\text { some months } \\
\text { break in } 2008 .\end{array}$ \\
\hline Østerild, DK & $\begin{array}{l}8.88080^{\circ} \mathrm{E} \\
57.04888^{\circ} \mathrm{N}\end{array}$ & $9 \mathrm{~m}$ & $250 \mathrm{~m}$ & 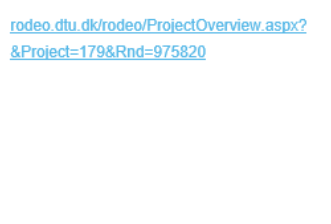 & Yoram Eisenberg & Ask nicely & $\mathrm{xlsx}$ & $\begin{array}{l}2015- \\
01-28-\end{array}$ & $\begin{array}{l}\text { Two } 250 \mathrm{~m} \\
\text { masts in } 4.3 \mathrm{~km} \\
\text { distance, both } \\
\text { instrumented. } \\
\text { Additionally, } 7 \\
\text { smaller masts } \\
\text { up to turbine } \\
\text { hub heights. }\end{array}$ \\
\hline Taggen, SE & $\begin{array}{l}14.519^{\circ} \mathrm{E} \\
55.8726^{\circ} \mathrm{N}\end{array}$ & $0 \mathrm{~m}$ & $100 \mathrm{~m}$ & $\begin{array}{l}\text { rodeo.dtu.dkrodeo/Proiectoverview. as XX? } \\
\text { \&.Project=1748Rnd }=758000\end{array}$ & Göran Loman & & & $\begin{array}{l}2014- \\
07-29 \text { to }\end{array}$ & $\begin{array}{l}\text { Offshore. } \\
\text { Owned by }\end{array}$ \\
\hline
\end{tabular}


2020:

- AWAKen (USA)

\begin{tabular}{l|l} 
WP2 Benchmarks & WP3 Optimal Use of Forecasting Solutions
\end{tabular}

\section{$f$ in}

Task 1.2 List of Field Campaigns

IEA Wind Task 36 Forecasting for Wind

Wnergy 1 lobal Coordination in Forecast

Model Improvement

January 10,2020

Helmut Frank (DWD), Irene Schicker (ZAMG), Will Shaw (PNNL)

Field measurement programs - Introduction

In IEA Wind Task 36 no experiments are made to compare Numerical Weather

Prediction (NWP) models with observations. However, there are work packages

trying to foster this comparison. Therefore, we compile a list of experiments

Lead

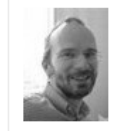

Helmut Frank

DWD, Deutscher

Wetterdienst

$\square$

which are particularly relevant for wind energy forecasting. We try to give a short

description of the experiments and some information on the data.

List of major field experiments in different

years

2021/2022

- AWAKEN (USA)

2020:

- FESSTVal (Germany)

2019:

- NEWA - Alaiz Experiment (ALEX17) (Spain)

2018:

- NEWA - Perdigão Experiment (Portugal)

2017:

- WFIP 2

- NEWA-Ferry Lidar Experiment (Baltic Sea)

- WIPAF (North Sea, Germany

2016:

- WFIP2 (USA)
Long list of

experiments,

linking to a larger

description.

Includes older

experiments with

open data.
2019:

2018:

- NEWA-Perdigão Experiment (Portugal)

2017

$$
\text { - WFIP } 2 \text { NEWA-Fery Lidar Experiment (Baltic Sea) }
$$

2016

- WFIP2 (USA)

NEWA- The coastal experiment RUNE (Denmark)

WEWA-Estenila Flow over heterogeneous roughness (Denma

NEWA-Hormamossen: flow over forested roting hilit

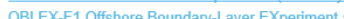

Fino1 (North Sea)

2015:

- WFIP2 (USA)

OBLEX-F1 Offshore Boundany-Layer EXperiment at Fino1 (North S MATERHORN-Fog 2 (USA)

2014

- alnap (Alps)

MATERHORN-Spring (USA)

2012 and older:

$$
\text { - MATERHORN-Fall (USA) }
$$

Major field experiments

The American Wake Experiment (AWAKEN) is a landmark collaborative

among the

plants today, leading to unexpected power losses and increased operations and maintenance costs. The AWAKEN campaign is designed to gathe

observational data to address the most pressing science questions about wind turbine wake interactions and aerodynamics and to further understand wake behavior and validate wind plant models. Simultaneously, the AWAKEN

campaign will also focus on testing of wind farm control strategies that have

been shown to increase wind plant power production. Leveraging the expertise and resources of a large body of National Laboratories, academic institutions, and industry parthers willead to improved wind farm layout with greater powe

costs. 


\section{Wind power prediction project list}

This list shows a large number of (mostly publically funded) research projects in short-term forecasting of wind power. The list is incomplete, as the emphas was a) on current projects, and b) on projects collected from the Task decades wons ttributed to forecasting (eg the IRP Wind or RAVE projects).

If you have additions or comments, please send them to the operating agent Gregor Giebel (grgi/at/ dtu.dk).

\begin{tabular}{|c|c|c|c|c|c|c|}
\hline Country & Project acronym & Full title & Sponsor & $\begin{array}{l}\text { Total / Funded } \\
\text { budget }\end{array}$ & Start - end date & $\begin{array}{l}\text { Participants (IEA } \\
\text { Task } 36 \\
\text { members in bold) }\end{array}$ \\
\hline DE & e-TWINS & $\begin{array}{l}\text { Verbundvorhaben: } \\
\text { e-TwINS } \\
\text { Ganzheitliche } \\
\text { digitale } \\
\text { Zwillingstechnologie } \\
\text { für das } \\
\text { Energiesystem }\end{array}$ & $\begin{array}{l}\text { BMWI } \\
\text { (Bundesministerium } \\
\text { für Wirtschaft und } \\
\text { Energie) }\end{array}$ & $\begin{array}{l}1.96 \mathrm{M} € / 1.96 \\
\mathrm{M€}\end{array}$ & $\begin{array}{l}\text { Jan } 2020 \text { - Dec } \\
2022\end{array}$ & $\begin{array}{l}\text { TU München } \\
\text { Windenergie, } \\
\text { Hochschule } \\
\text { München, Zsw, } \\
\text { Mesh } \\
\text { Engineering }\end{array}$ \\
\hline EU & Smart4RES & $\begin{array}{l}\text { Next Generation } \\
\text { Modelling and } \\
\text { Forecasting of } \\
\text { Variable } \\
\text { Renewable } \\
\text { Generation for } \\
\text { Large-scale } \\
\text { Integration in } \\
\text { Energy Systems } \\
\text { and Markets }\end{array}$ & EU Horizon2020 & $4 \mathrm{ME} / 4 \mathrm{ME}$ & $\begin{array}{l}1 \text { Nov } 2019-30 \\
\text { Apr } 2023\end{array}$ & $\begin{array}{l}\text { Armines, DTU, } \\
\text { INESC TEC, } \\
\text { EDP, Meteo- } \\
\text { France, emsys, } \\
\text { DNV GL, Whiffle, } \\
\text { Dowel, ICCS, } \\
\text { HEDNO, DLR }\end{array}$ \\
\hline EU & EOCOE II & $\begin{array}{l}\text { Energy Oriented } \\
\text { Center of } \\
\text { Excellence : } \\
\text { toward exascale } \\
\text { for energy }\end{array}$ & EU Horizon2020 & $9.2 \mathrm{ME}$ & $\begin{array}{l}\text { 1.1.2019- } \\
\text { 31.12.2021 }\end{array}$ & $\begin{array}{l}18 \text { teams in } 7 \\
\text { countries } \\
\text { including } \\
\text { Fraunhofer IEE }\end{array}$ \\
\hline DK & [link] & $\begin{array}{l}\text { IEA Wind Task } \\
36 \text { Phase II } \\
\text { Danish } \\
\text { Consortium }\end{array}$ & $\begin{array}{l}\text { EUDP (national } \\
\text { Danish funding) }\end{array}$ & $500 \mathrm{k} € / 300 \mathrm{k} €$ & $\begin{array}{l}1 \text { Jan } 2019 \text { - } 31 \\
\text { Dec } 2021\end{array}$ & $\begin{array}{l}\text { DTU, ConWX, } \\
\text { ENFOR, DNV, } \\
\text { WEPROG, Ea } \\
\text { Energianalyse, } \\
\text { Energinet }\end{array}$ \\
\hline
\end{tabular}




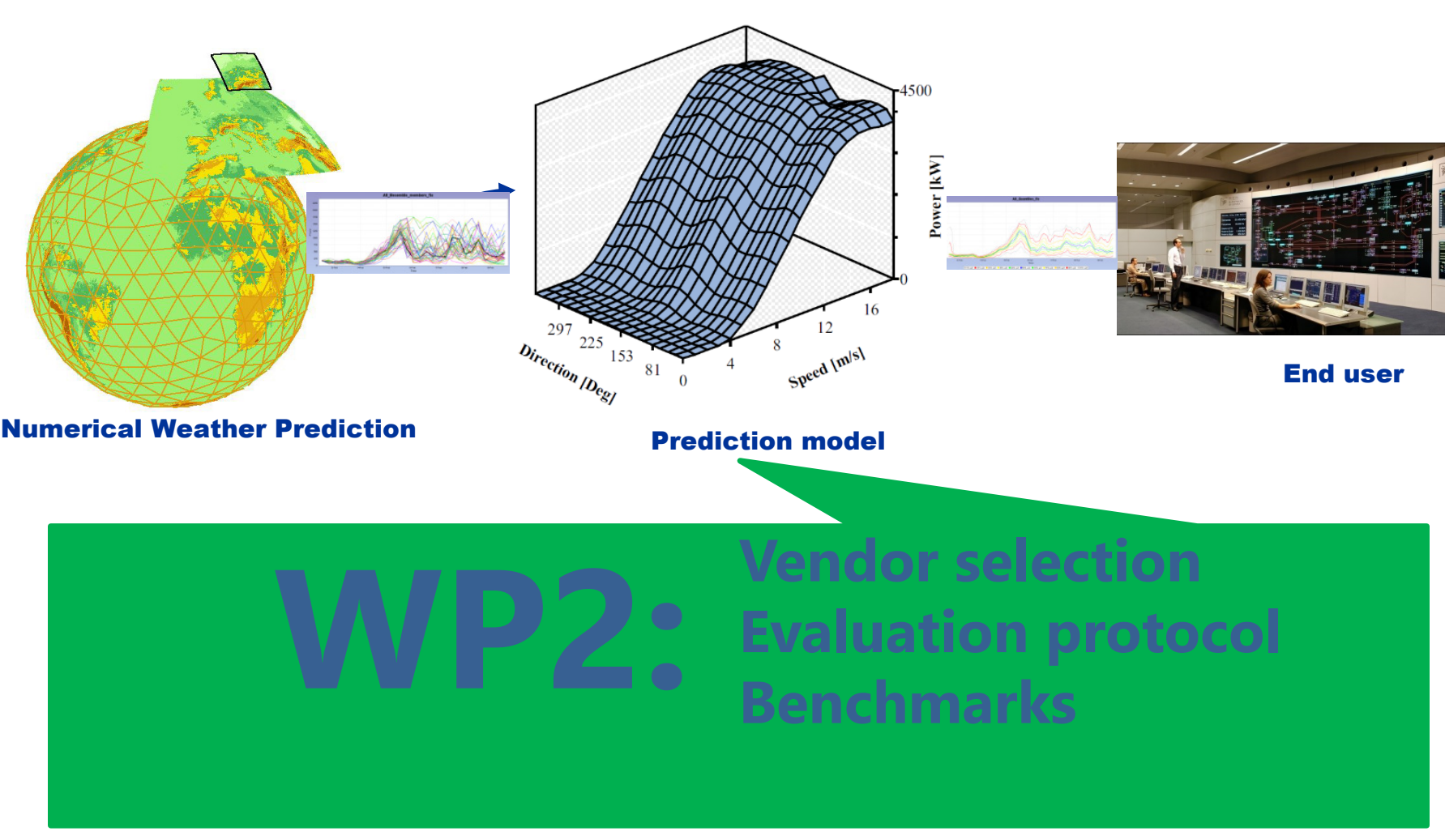




\section{WP2 Benchmarks}

Lead: Caroline Draxl, NREL John Zack, UL Pierre Pinson, DTU Elektro
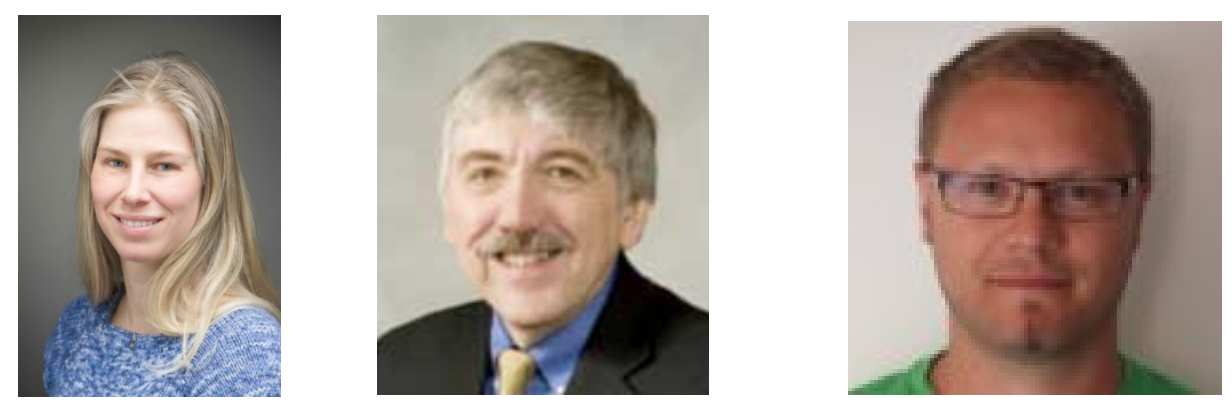


\section{Additional information:}

RE-Europe:

Full data set can be downloaded as zip-file. Generation signals and forecasts and meta data on location and aggregation are stored in csv-files. Additional to wind power data the data set includes solar generation and power load data More information can be found on hittps://zenodo. org/record

135177\#.WamNAzclFmB. Data policy: Creative Commons AttributionNonCommercial 4.0.

NREL WIND Toolkit: 


\section{Work Package 2.1:}

Recommended Practice for Optimal Forecast Solution Selection Slides by John Zack and Corinna Möhrlen 


\section{The Problem and an Approach for a Solution}

- Documented Benefits:

- Use of forecasts can lower variable generation integration costs while maintaining the required high system reliability

- Problem:

- A substantial amount of value is not realized due to the use of non-optimal forecast solutions by users

- Wrong forecast performance objective(s)

- Poorly designed and executed benchmarks/trials

- Use of non-optimal evaluation metrics

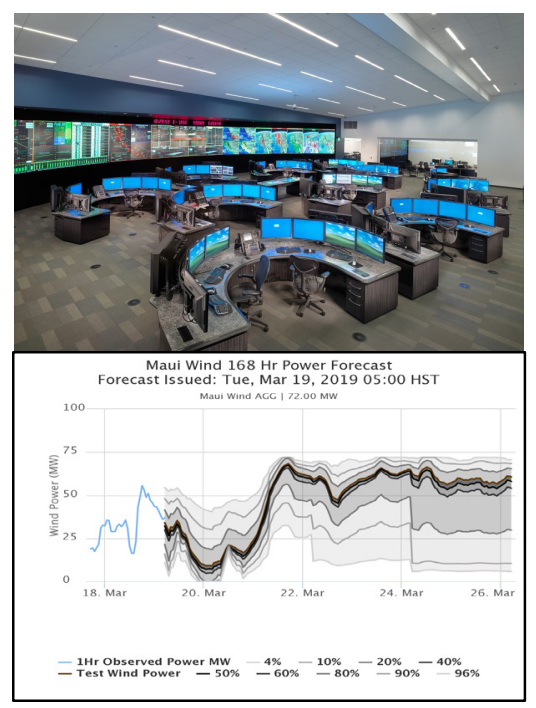

- Potential Mitigation:

- IEA Wind Task 36 - Work Package 2 experts formulated a set of "best practices" for selecting and running wind forecasting solutions 


\section{Overview of IEA-WIND Recommended Practice}

for the Selection of Wind Power

Forecasting Solutions (WP 2.1)

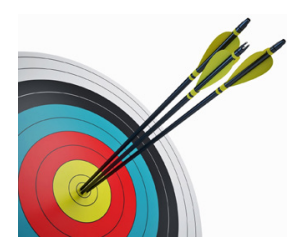

Target: Compile guidance for the implementation of renewable energy forecasting into system operation

Approach: Develop a set of 3 documents that specify IEA Wind Recommended Practices for:

3

Parts
1. Forecast Solution Selection Process

2. Design and Execution of Benchmarks and Trials

3. Evaluation of Forecasts and Forecast Solutions

Current Status: Released

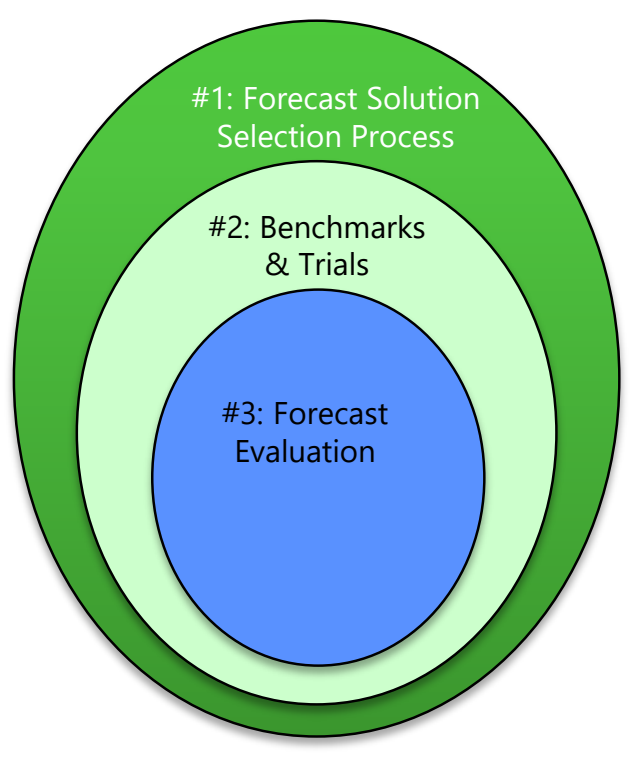

- Available Online: http://www.ieawindforecasting.dk/publications/recommendedpractice 


\section{IEA Best Practice Recommendations for the Selection of a Wind Forecasting Solution: Set of 3 Documents}
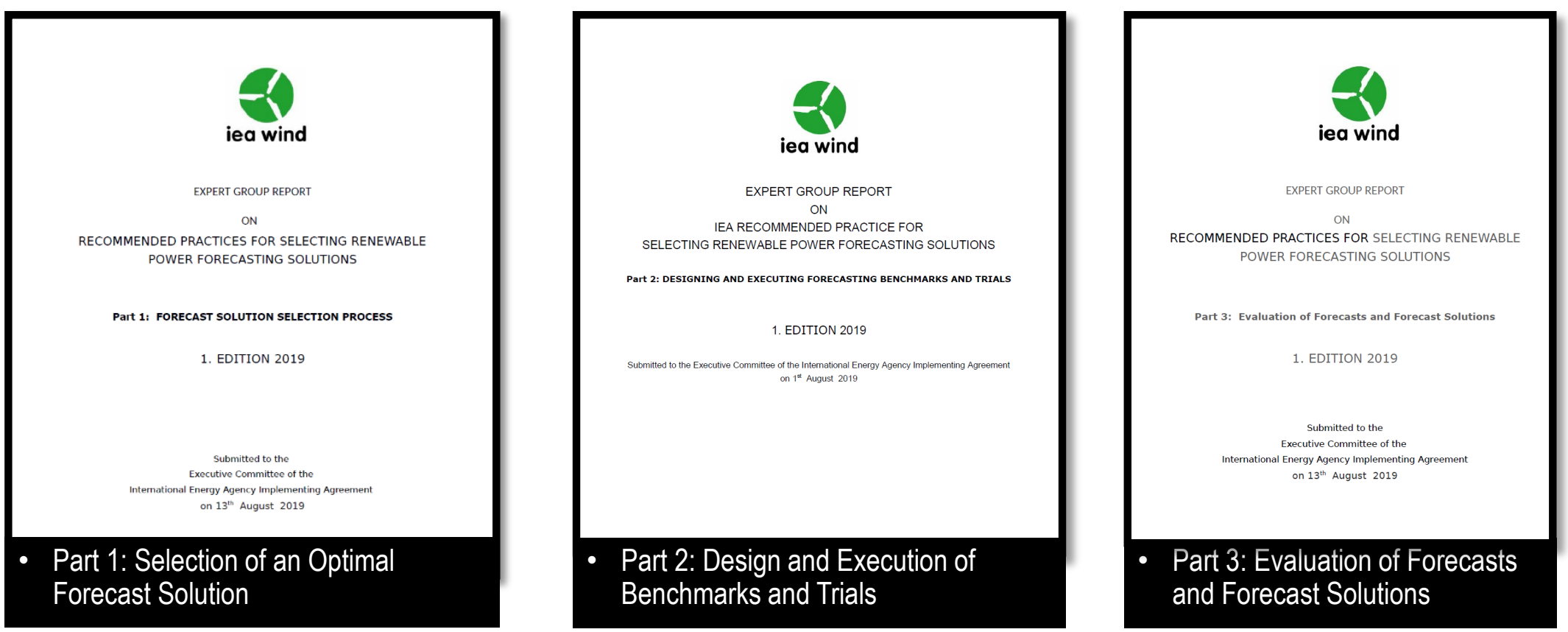


\section{Part 1: Forecast Solution Selection Process:}

- Key Concept: the "best" practical forecast solution process for an application depends on the user's access to knowledge, labor resources and time

- Conducting a performance trial may not profile useful guidance if not well designed and executed

- Alternative approaches to trials may be more effective

- Key Guidance:

- Decision Support Tool: guidance to determine the best approach for a specific situation

- Check lists of information to gather for trials, RFP, RFI

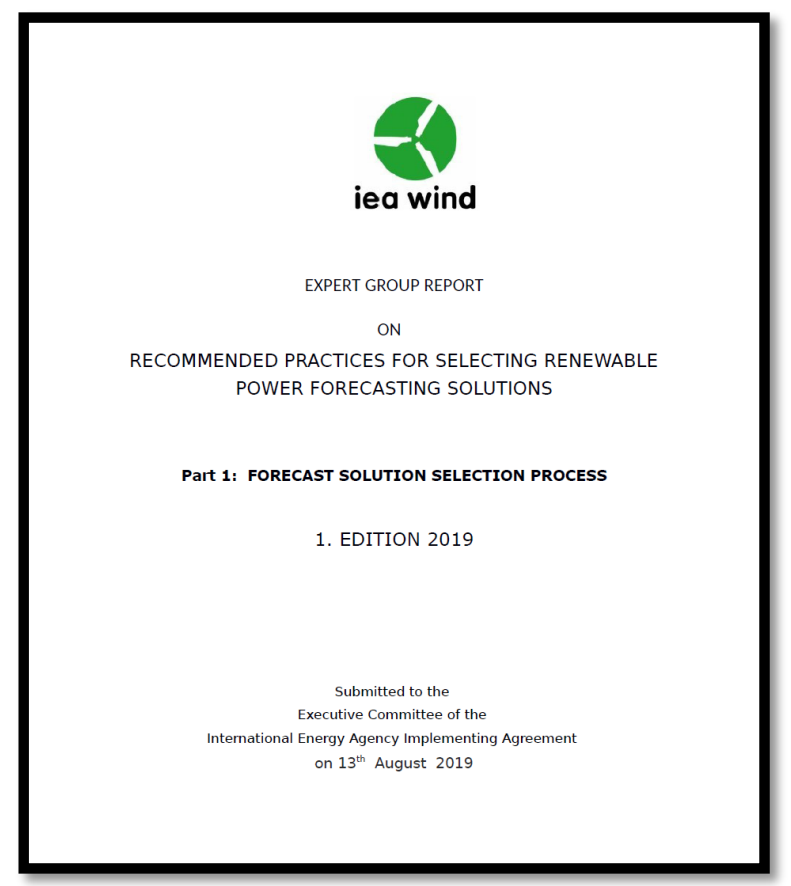




\section{IEA Task 36 WP2.1}

FORECAST SOLUTION SELECTION AND TRIAL/BENCHMARK EXECI

- Content Examples:

- Decision Support Tool to find best path for appropriate solution

- Summary trial/benchmark checklist for all end-users

- Appendices with

- meta-, historical-, and real time-data details to make communication more efficient

- Forecast file format sample

- Questions to ask in RFI/RFP

- Detailed steps during the three main phases of a trial: preparation, during, and post-trial

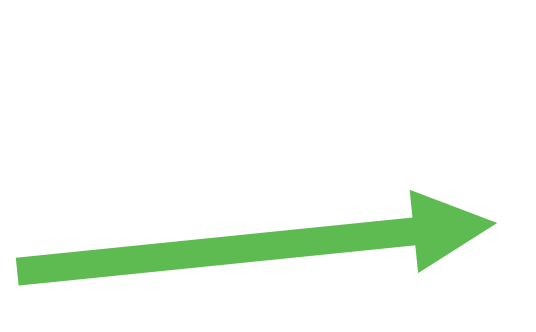

Consult expert with trial experience

$\square$ Establish timeline and winning criteria

Decide on live or retrospective trial

Dether medata (use EA checklist spreadsheet)

Determine if adequately resourced to carry o

Invite Forecost Service

$\square$ Distribute historical and meta-data

$\square$ Allow two weeks Q\&A prior to trail start

$\square$ Begin Trial

--During Trial-

$\square$ Develop validation report

$\square$ Provide interim results (if no live data being provided)

$\square$ Provide final results

Notify winner(s)

$\square$ Contract with winner(s)

$\square$ Start Service

Post Trial--

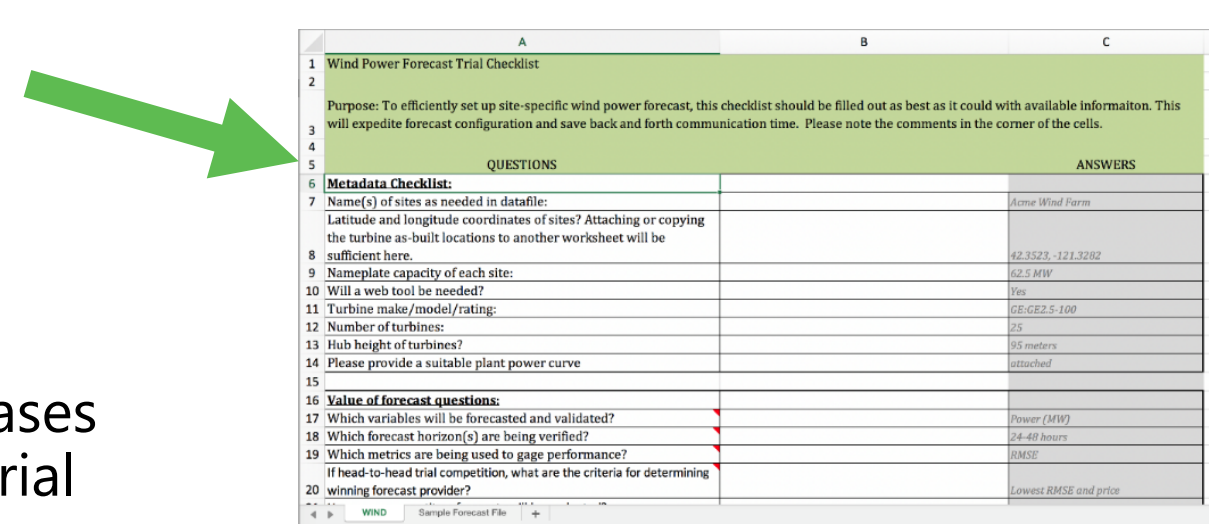




\section{Key Elements of Recommended Practices for Forecast Solution Selection}

- Selection/update of forecasting solutions in which Quality, Reliability and Price are in perfect harmony is usually a complex task

- Forecast IT infrastructure and solution architecture need careful considerations

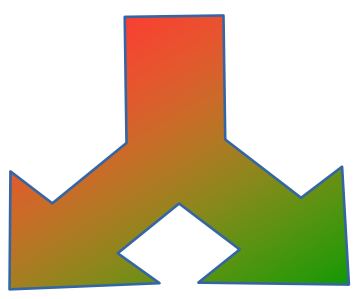

$\rightarrow$ provides decision support for basic elements common to all forecast solutions

$\rightarrow$ encourages end-users to analyze their own situation

$\rightarrow$ encourages users to request a forecasting solution that fits their own purposes $\rightarrow$ discourages to just

"do what everybody else is doing"

$\rightarrow$ discourages seeking a simple or cheap solution if the application is complex 


\section{Decision Support Tool for the Process of Selecting a Forecasting Solution}

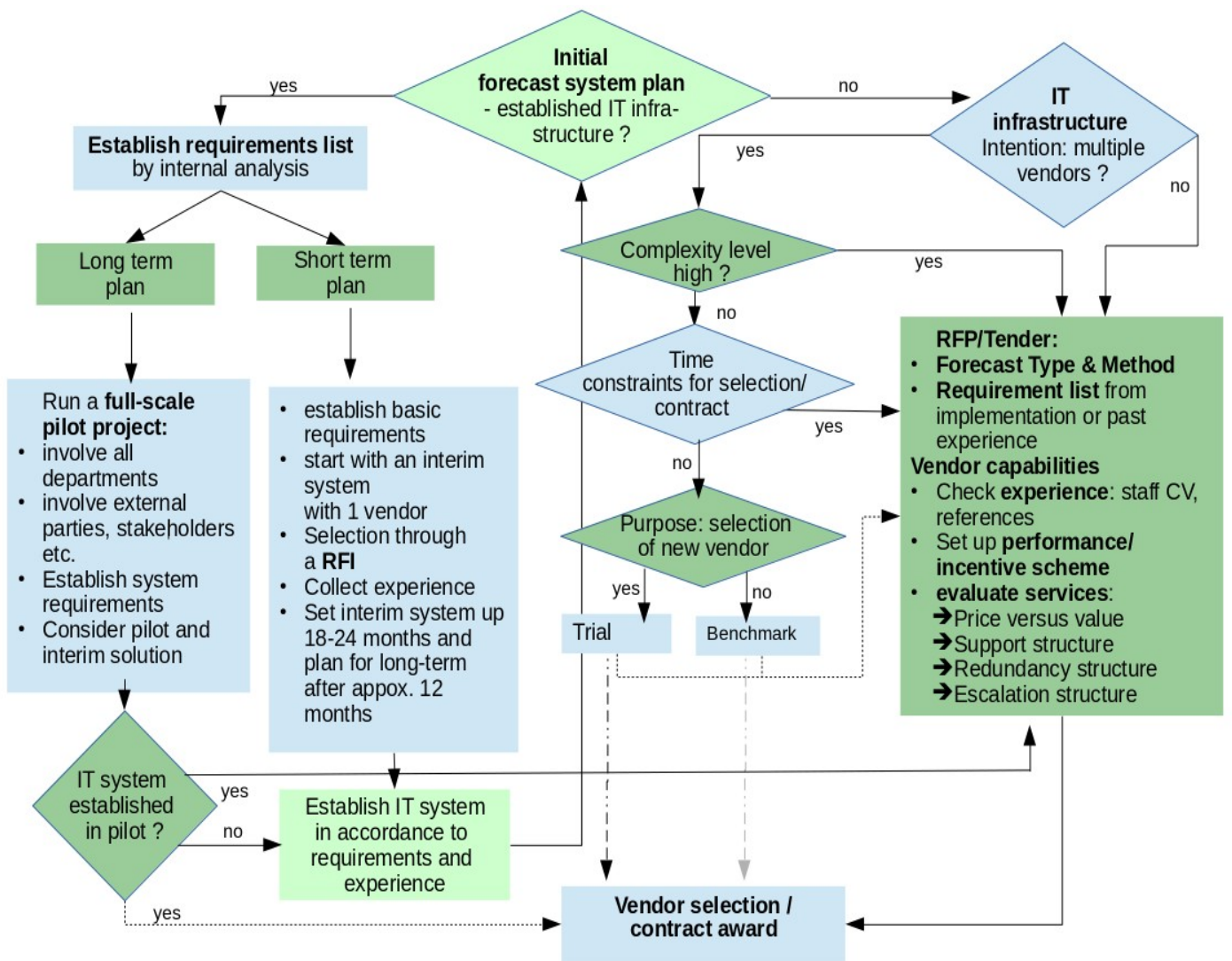

- Provides guidance and practical examples for:

$\circ$ the formulation of a process to select an optimal forecasting solution

$\circ$ analysis and formulation of forecasting requirements

$\circ$ assessing vendor capabilities with and without trials 


\section{Part 2: Designing and Executing Forecasting Benchmarks and Trials}

- Key Concept: a benchmark or trial must be carefully designed, executed and evaluated in order to produce meaningful information that can be used for effective decision-making

- Many decisions are based on "noise" (random results) produced by benchmarks/trials

- Key Guidance:

- Best practices for the design, execution and evaluation of trial/benchmarks

o Examples of "pitfalls to avoid"

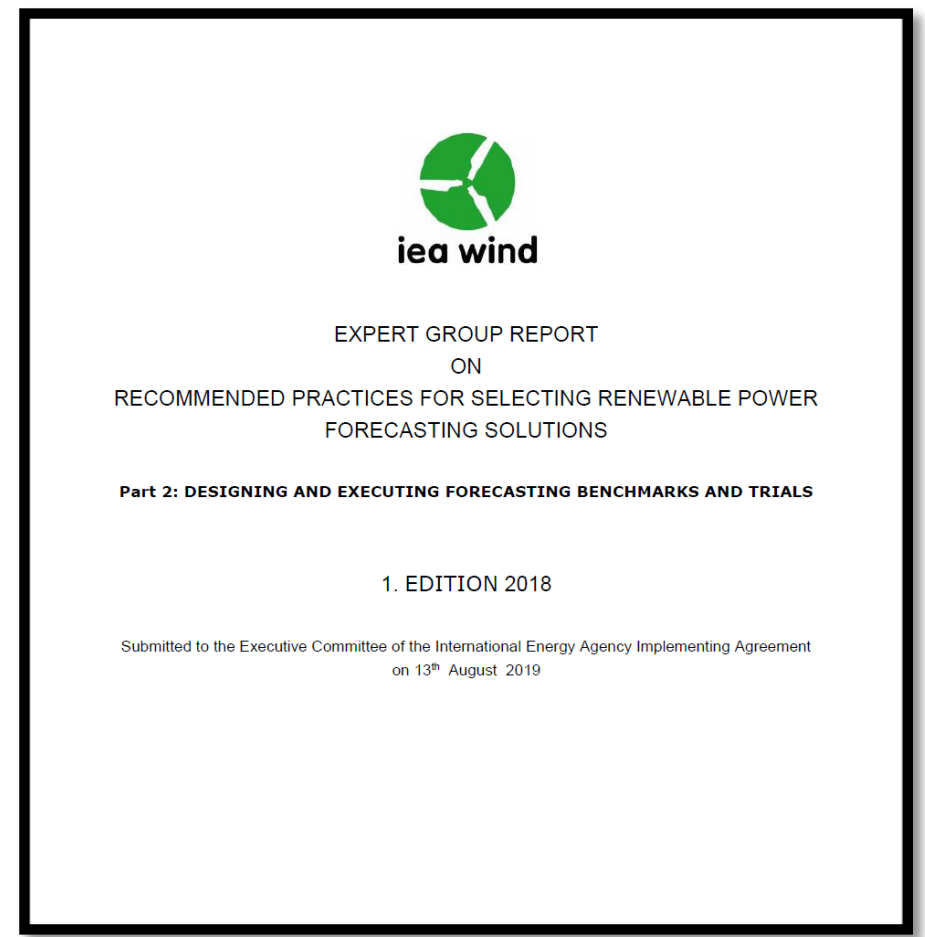




\section{The 3 Phases of a Benchmarking Process: \#1}

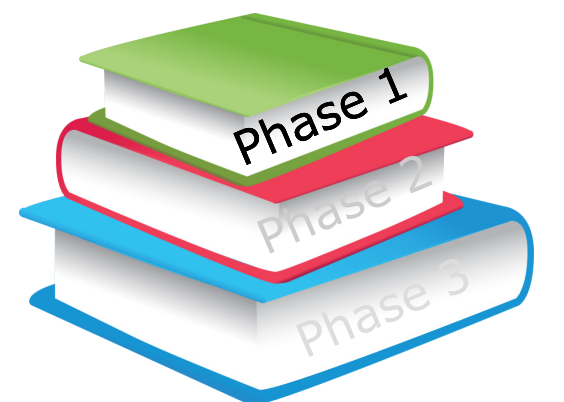

$$
\begin{gathered}
\text { Preparation Phase: } \\
\text { determining the scope and focus } \\
\text { of the performance evaluation }
\end{gathered}
$$

Forecast horizons (look-ahead time periods)

Available historical data

Appropriate length of benchmark

Are conditions during benchmark representative?

Meaningful evaluation metrics

Think of what factors are most important as in any big or long-term purchase (e.g. home, car, forecasting system)? 


\section{The 3 Phases of a Benchmarking Process: \# 2}

\section{Execution Phase: ensuring a fair and representative process}

- Data monitoring (forecasts and observations)

- For fairness and transparency: test accuracy and delivery performance.

- Monitor forecast receipt (reliability)

- Sample should be normalized (all forecasters evaluated for same period \& locations)

- Develop and refine the evaluation scripts 


\section{The 3 Phases of a Benchmarking Process: \#3}

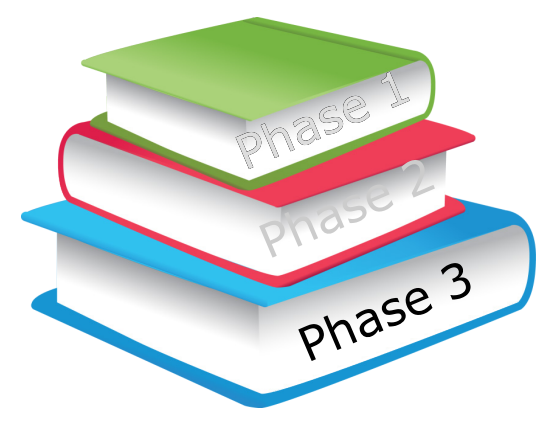

\section{Analysis Phase:}

compiling a comprehensive and relevant assessment

- Critical Evaluation Criteria:

- Application-relevant accuracy of the forecasts

- Performance in the timely delivery of forecasts

- Ease of working with the forecast provider

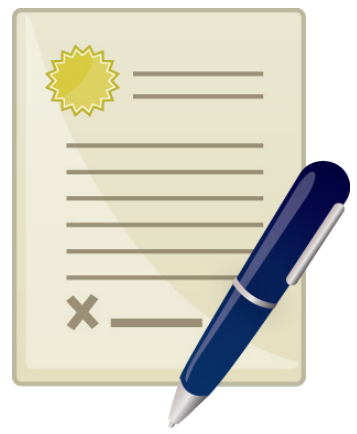




\section{Examples of Benchmarking Piffalls to Avoid}

- Poor communication with forecast providers

- All providers not provided with the same set of information

- Incumbent providers having an information advantage by default

- Unreliable comparisons

- Forecasts for different time periods are compared (evaluated)

- Forecasts for different facilities/portfolios are compared (evaluated)

- Bad design

- Short trials in unrepresentative periods (e.g. 1 month in a low wind season)

- No on-site data given to forecast providers

- Intra-day forecasts made from once-a-day target-site data update

\section{- Details missing or not communicated to providers}

- No documentation of daylight savings time changes in data files

- No specification of whether data time stamp represents interval beginning or ending

- No documentation of plant capacity changes in historical data or trial period

- Curtailment and maintenance outages not provided

- Opportunities for "cheating" not eliminated

- No penalty for missing forecasts ( possible no submission in difficult situations)

- Forecast delivery times not enforced (could submit later forecasts)

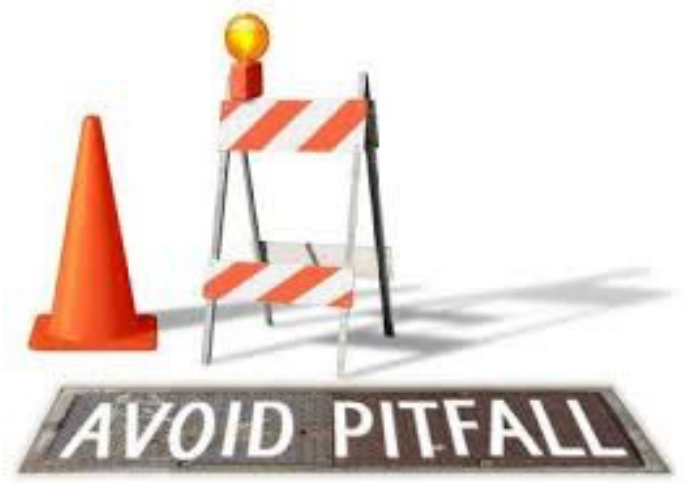




\section{Part 3: Evaluation of Forecasts and Forecast Solutions}

- Key Concept: all forecast performance evaluations have a degree of uncertainty that is a composite from a number of factors

- Management of evaluation uncertainty should be a priority in order to maximize signal/noise

- Poor management of uncertainty may result in evaluation information being dominated by noise

- Key Guidance:

- Three key attributes of an evaluation process

- Factors and issues associated with each attribute

o Approaches to minimize evaluation uncertainty

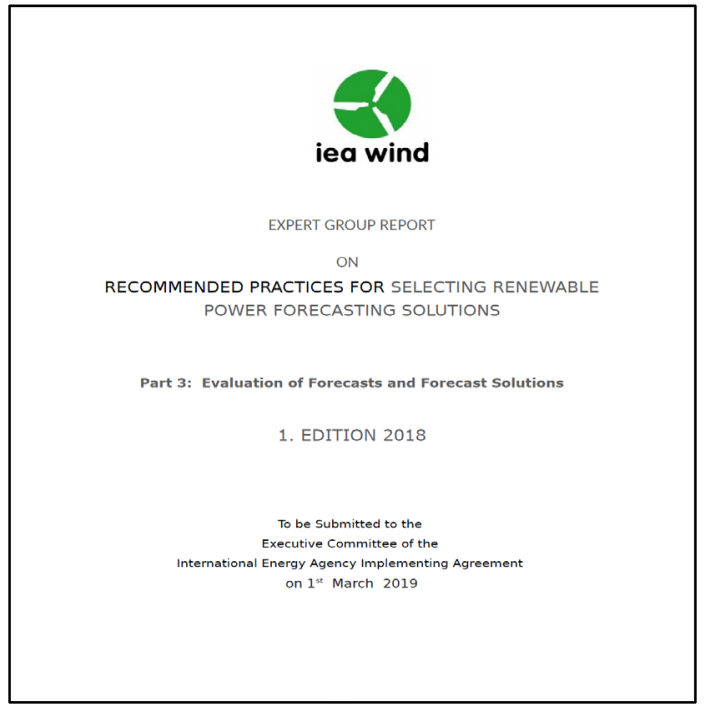




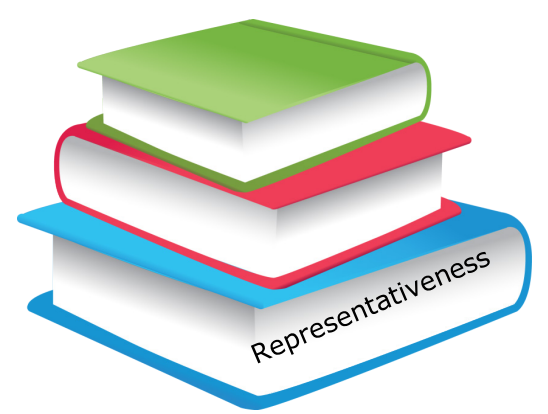

Representativeness: relationship between the results of a forecast performance evaluation and the performance that is ultimately obtained in the operational use of a forecast solution

- Statistically meaningful evaluation sample size and composition

- High quality data from the forecast target sites

- Formulation and enforcement of rules governing the submission of forecasts ("fairness")

- Availability of a complete and consistent set of evaluation procedure information to all evaluation participants ("transparency") 
Three Critical Factors to Achieve a Meaningful Trial: \#2

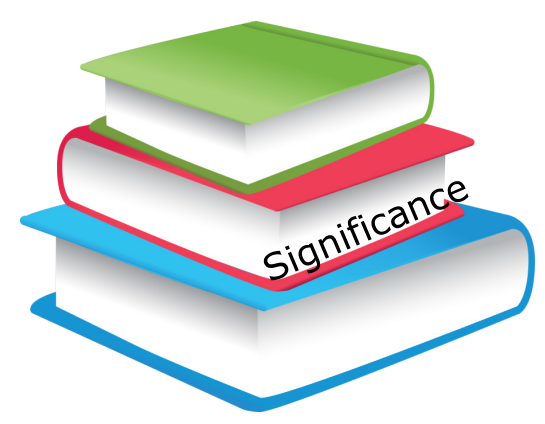

Significance: ability to differentiate between performance differences that are due to noise in the evaluation process and those that are due to meaningful differences in skill among forecast solutions

- Minimize noise in the evaluation sample (i.e. lower the uncertainty)

- Quantify the uncertainty in performance metrics

- Consider performance uncertainty bands when evaluating performance differences among candidate solutions 


\section{Three Critical Factors to Achieve a Meaningful Trial: \#3}

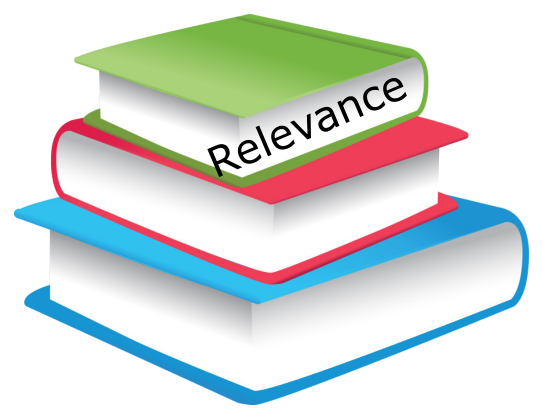

Relevance: degree of alignment between the evaluation metrics used for an evaluation and the true sensitivity of a user's application(s) to forecast error

- Ideal Approach: formulate a cost function that transforms forecast error to the application-related consequences of those errors (often very difficult)

- Practical Alternative: use a matrix of performance metrics that measure a range of forecast performance attributes

-When using more than one relevant metric:

- Remember: ONE forecast can NOT be optimal for more than one metric;

- Use separate forecast optimized for each metric if that attribute of performance is critical

- When employing multiple ("N") forecast solutions: choose the set that provides the best composite performance NOT the "N" best performing solutions 


\section{Forecast Performance Perception and Optimization:}

\section{Example of the Impact of Metric Selection}

- Ramp forecast example

- Typical case: user is interested in forecasting occurrence and attributes of ramp events for operational decisionmaking

- User evaluates forecast with a widely-used global metric such as MAE

- Provider optimizes to the user's selected metric

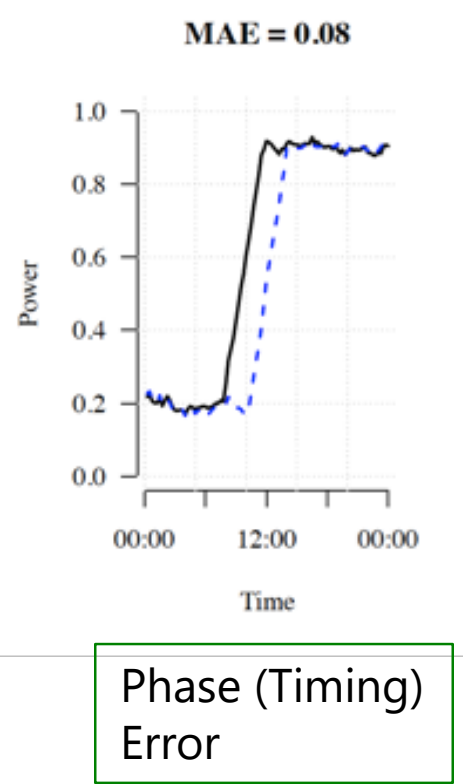

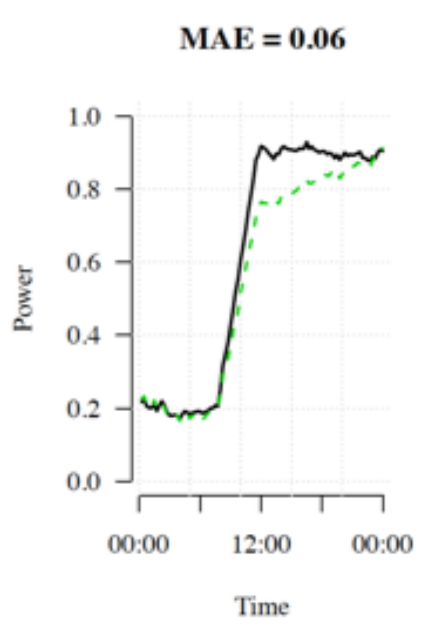

Amplitude

Error

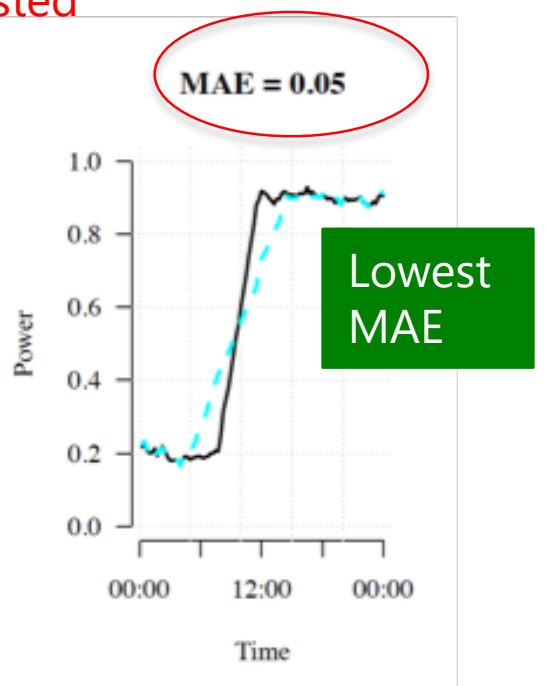

Ramp Rate Error

Verifying a ramp forecast with MAE/RMSE brings the forecast service provider into a dilemma: Tuning of forecast can (1) create good MAE scores or (2) serve the customer's needs $\rightarrow$ NOT BOTH 


\section{Key Points of Part 3}

- All performance evaluations of potential or ongoing forecast solutions have a degree of uncertainty

- The uncertainty is associated with three attributes of the performance evaluation process evaluation process: (1) representativeness, (2) significance and (3) relevance

- A carefully designed and implemented evaluation process that considers the key issues in each of these three attributes can minimize the uncertainty and yield the most meaningful evaluation results

- A disregard of these issues is likely to lead to uncertainty and/or decisions based on unrepresentative information 


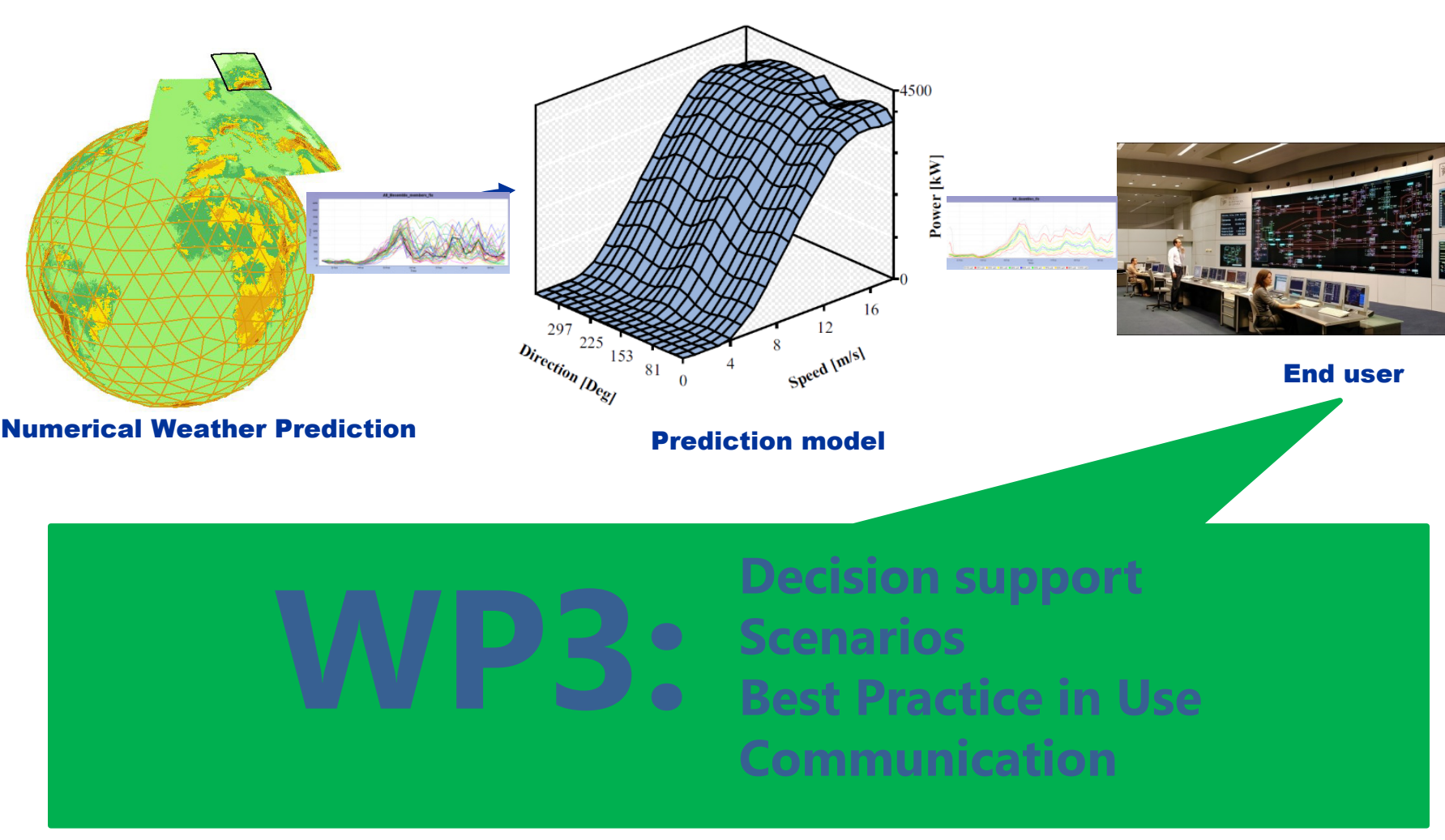




\section{WP3 Advanced Usage}

Lead:

Corinna Möhrlen, WEPROG

Ricardo Bessa, INESC TEC

George Kariniotakis, Mines ParisTech
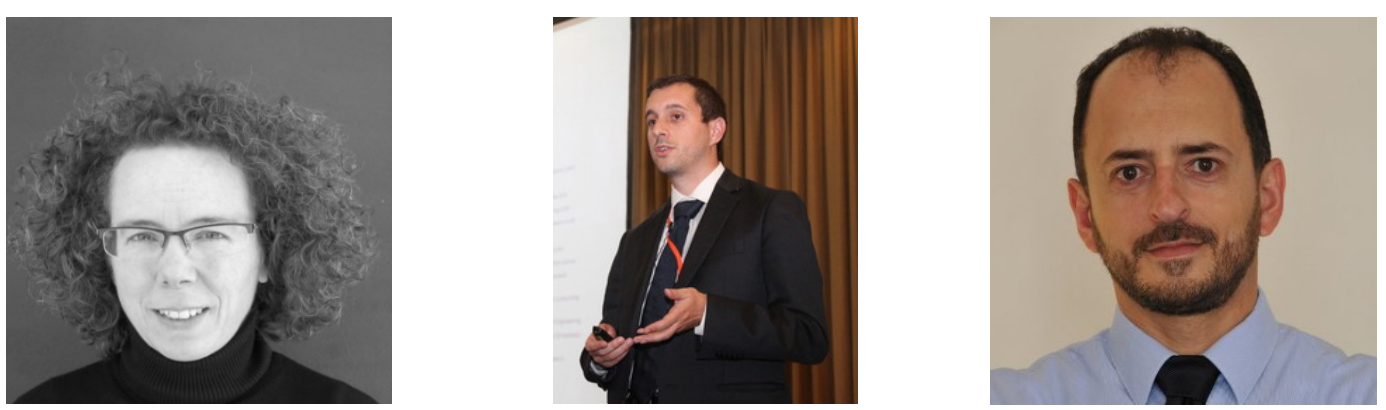
15th Int. Workshop on Large-Scale Integration of Wind Power into Power Systems as well as on Transmission Networks for Offshore Wind Farms, Vienna, 15 - 17 November, 2016

\section{Use of Forecast Uncertainties in the Power Sector: State-of-the-Art of Business Practices}

C. Möhrlen*, R. J. Bessa ${ }^{\dagger}$, M. Barthod ${ }^{\ddagger}$, G. Goretti ${ }^{\S}$ and M. Siefert ${ }^{ף}$ *WEPROG ApS, Assens, Denmark, Email: com@ weprog.com

${ }^{\dagger}$ INESC TEC, Porto, Portugal, Email: ricardo.j.bessa@ inesctec.pt

meteo*swift, Toulouse, France, Email: morgane.barthod@meteoswift.com

$\S$ Dublin Institute of Technology, Ireland, Email: gianni.goretti@mydit.ie
Fraunhofer IWES, Kassel, Germany, Email: malte.siefert@iwes.fraunhofer.de

Abstract-The work we present is an investigation on the state-of-the-art use of forecast uncertainties in the business practices of actors in the power systems sector that is part of the
"IEA Wind Task 36: Wind Power Forecasting". The purpose of this tak is to get an overview of the current use and applise of of probabilistic forecasts by actors in the power industry and investigate how they estimate and deal with uncertainties. The authors with expertise in probabilistic forecasting have been gathering information from the industry in order to identify the areas, where progress is needed and where it is difficult to achieve further progress. For this purpose, interview question were compiled for different branches in the power industry six months of 2016 . At this stage, we present and discrs results from this first round of interviews and draw preliminary conclusions outlining gaps in current forecasting methodologies and their use in the industry. At the end we provide some recommendations for next steps and further development with the objective to formulate guidelines for the use of uncertainty

$$
\text { I. Introduction }
$$

oughly goes with wind speed to the power of three, an mall errors and uncertainties are thus amplified and have a even higher impact compared to wind speed uncertaintie Weather development associated with fronts moving ove large areas where wind is increasing rapidly over a short time are the most critical situations for a balance responsible party or a transmission system operator (TSO): it is under these circumstances that a deterministic forecast may be strongly incorrect and suppress steep ramping that can cause system security issues as well as large imbalances. Translated in he market it means that there can be a sudden lack of power doning a downer power dit can be down-reglated fast an efficitly, which power tas can be down ef wesults in curailnent. As long as the penetraion levet of wind is below $20 \%$ of generation, such uncertainty can usually be dealt with with a reasonable amount of reserves. As penetration increases, or in the case of island grids or badly interconnected grids, reserves and ancillary services grow above a desirable leve

The relevance of forecast uncertainties for wind power and other renewable energies grows as the penetration of these sources in the energy mix increases. Once a certain level of penetration is reached, ignoring the reliability of use of uncertainty forecasts and to find the gaps in the understanding of uncertainties and the associated forecasting tools and methods, we have been carrying out a study with 


\section{Use of probabilistic forecasting}

Open Access journal paper

48 pages on the use of uncertainty forecasts in the power industry

Definition - Methods Communication of Uncertainty - End User Cases - Pitfalls - Recommendations

Source: http://www.mdpi.com/1996-1073/10/9/1402/
F energies

MDPI

Review

Towards Improved Understanding of the

Applicability of Uncertainty Forecasts in the Electric

Power Industry

Ricardo J. Bessa ${ }^{1, *} \odot$, Corinna Möhrlen ${ }^{2} \odot$, Vanessa Fundel ${ }^{3}$, Malte Siefert ${ }^{4}$, Jethro Browell ${ }^{5} \odot$, Sebastian Haglund El Gaidi ${ }^{6}$, Bri-Mathias Hodge ${ }^{7}$, Umit Cali ${ }^{8}$ and George Kariniotakis ${ }^{9}$

1 INESC Technology and Science (INESC TEC), 4200-465 Porto, Portugal

WEPROG, 5610 Assens, Denmark; com@weprog.com

Fraunhofer Institute for Wind Energy and Energy System Technology (IWES), 34119 Kassel, Germany; malte.siefert@iwes fraunhofer.de

University of Strathclyde, De
jethro.browell@strathacuu

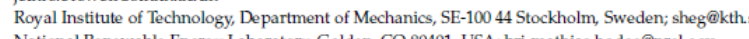
National Renewable Energy Laboratory, Golden, CO 80401, USA; bri-mathias.hodge@nrel.gov

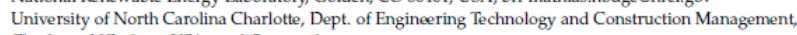
Charlotte, NC 28223, USA, ucalieuncc.edu

MINES Paris Tech, PSL Research University, Centre for Processes, Renewable Energies and Energy Systems (PERSEE), 06904 Sophia Antipolis Cedex, France; georges.kariniotakis@mines-paristech.fr Academic Editor: David Wood Academic Editor. Dand Wood

Abstract: Around the world wind energy is starting to become a major energy provider in electricity markets, as well as participating in ancillary services markets to help maintain grid stability. The reliability of system operations and smooth integration of wind energy into electricity markets has been strongly supported by years of improvement in weather and wind power forecasting systems. Deterministic forecasts are still predominant in utility practice although truly optimal decisions and risk hedging are only possible with the adoption of uncertainty forecasts. One of the main barriers for the industrial adoption of uncertainty forecasts is the lack of understanding of its information content (e.g., its physical and statistical modeling) and standardization of uncertainty forecast products, which frequently leads to mistrust towards uncertainty forecasts and their applicability in practice. This paper aims at improving this understanding by establishing a common terminology and reviewing the methods to determine, estimate, and communicate the uncertainty in weather and wind power forecasts. This conceptual analysis of the state of the art highlights that (i) end-users should start to look at the forecast's properties in order to map different uncertainty representations to specific wind energy-related user requirements; (ii) a multidisciplinary team is required to foster the integration of stochastic methods in the industry sector. A set of recommendations for standardization and improved training of operators are provided along with examples of best practices 


\section{Broader paper on uncertainty forecasting}

Prediction Models

Designed to

Prevent Significant

Errors

By Jan Dobschinski, Ricardo Bessa, Pengwei Du,

Kenneth Geisler,

Sue Ellen Haupt,

Matthias Lange,

Corinna Möhrlen,

Dora Nakafuji, and

Miguel de la Torre Rodriguez

Uncertainty Forecasting in a Nutshell

DOI: 10.1109/MPE.2017.2729100

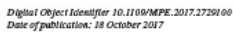

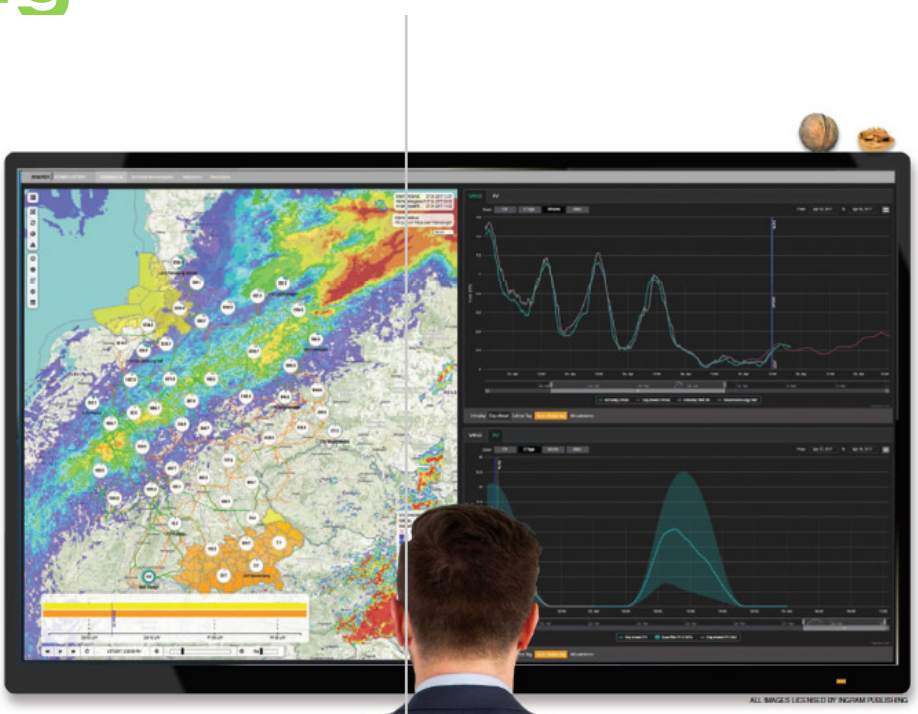

TIS IN THE NATURE OF CHAOTIC ATMOspheric processes that weather forecasts wi
never be perfectly accurate. This natural fact poses challenges not only for private life, public safety, and traffic but also for electrical power systems with high shares of weather-depende To frilitte a secure and ebor

market integration of renewable energy sources (RES), grid operators and electricity traders mus rems will produce over the sent hours und has. This is why RES forecast models have grown over the past decade to become indispensable tools for many stakeholdders in the energy economy. Driven by increased gnid stability requirements and mar-
ket forces, forecast systems have become tailores to the end user's application and already perfon reliably over long periods. Apart from a residually moderate forectast error, there are single extrent.

Nevertheless, there are also forecast systert

that provide additional information about the

expected forecast uncertainty and estimations of both moderate and extreme enrors in addition casts warn the grid operator to prepare to take spe cial actions to ensure grid stability.

The State of the Art

A oped specifically to predict the power produc. tion of single wind and solar units, differently sized portfolios, local transformer stations and
subgrids, distribution and transmission grits, and entire countries. Nearly all forecast systems have one thing in common: they rely on numerical weather predictions (NWPs) to calculate the expected RES power production. The way 10 casts depends crucially on the end user's application and the available plant configuration and measurement data. If historical measurements are

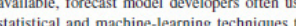
automatically find a relation between historical weather forecasts and simultaneously observed power measurements. If no historical measure-

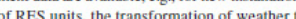
power is offen accomplished by physically based models that consider the unit's parameters to map the internal physical processes. 


\section{Minute-scale forecasting}

Open Access review journal paper: 30 pages on minute-scale forecasting of wind power inclusive review on data assimilation techniques, probabilistic methods.

Use of minute-scale forecasting: (1) wind turbine and wind farm control, (2) power grid balancing, (3) energy trading and ancillary services

Source:https://www.mdpi.com/1996-1073/12/4/712

Energies 2019, 12, 712; doi:10.3390/en12040712 www.mdpi.com/journal/energies energies

Minute-Scale Forecasting of Wind Power-Results from the Collaborative Workshop of IEA Wind Task 32 and 36

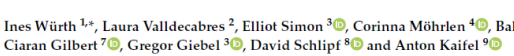

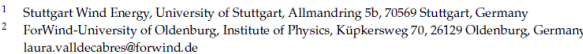

University of Denmark, Frederikborgrvei 399, 4000 Roski

Denmark; ellsim@đdu.dk (E.S.); grgi@dtu.dk (G.G.)

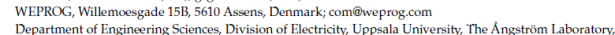

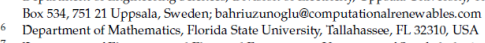

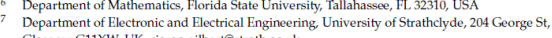

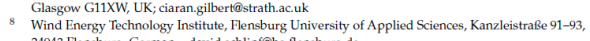

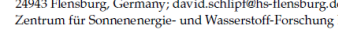

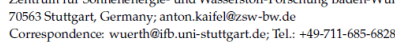

Received: 14 December 2018; Accopted: 14 February 2019; Published: 21 February 2019

Abstract: The demand for minute-scale forecasts of wind power is continuously increasing with the growing penetration of renewable energy into the power grid, as grid operators need to ensure
grid stability in the presence of variable power generation. For this reason, IEA Wind Tasks 32

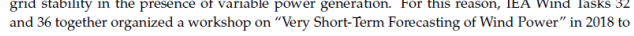
discuss different approaches for the implementation of minute-scale forecessts into the power industry.
IEA Wind is an international platorm for the research community and industry. Task 32 tries to (a)

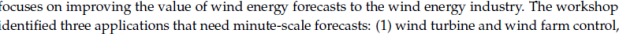
(2) power grid balancing, (3) energy trading and ancillary services. The forecasting horizons for control applications The methods that can be applied to generate minute cacale forket and grid upstream data from remote sensing devices such as scanning lidars or radars, or are based on point measurements from met masts, turbines or profiling remote sensing devices. Upstream data needs
to be propasated with advection models and pingt measurements can esther be to be propagated with advection models and point measurements can either be used in statistical
time series models or assimilated into physical models. All methods have advantages but olso shortcomings. The workshop's main conclusions were that there is a need for further investigations into the minute-scale foreceasting methods for different use cases, and a cross-disciplinary exchange of different method experts should be estabisished. Additionally, more efforts should be directed

Keywords: wind energyy minute-scale forecasting; forecasting horizon; Doppler lidar; Doppler radar;
numerical weather prediction models 


\section{WP3 End use Workshop Glasgow}

"Maximising Value from State-of-the-art Wind Power Forecasting Solutions" Strathclyde University, Glasgow, 21 Jan 2020

- Talks by academia and industry (e.g. UK National Grid)

- Open Space discussion on RP, data and forecast value

- Game on value of probabilistic forecasts (feel free to play it yourself!): https://mpib.eu.qualtrics.com/jfe/form/SV d5aAY95q2mGI8El

- Streamed on YouTube: https://www.youtube.com/watch?v=1NOIr7jluXI

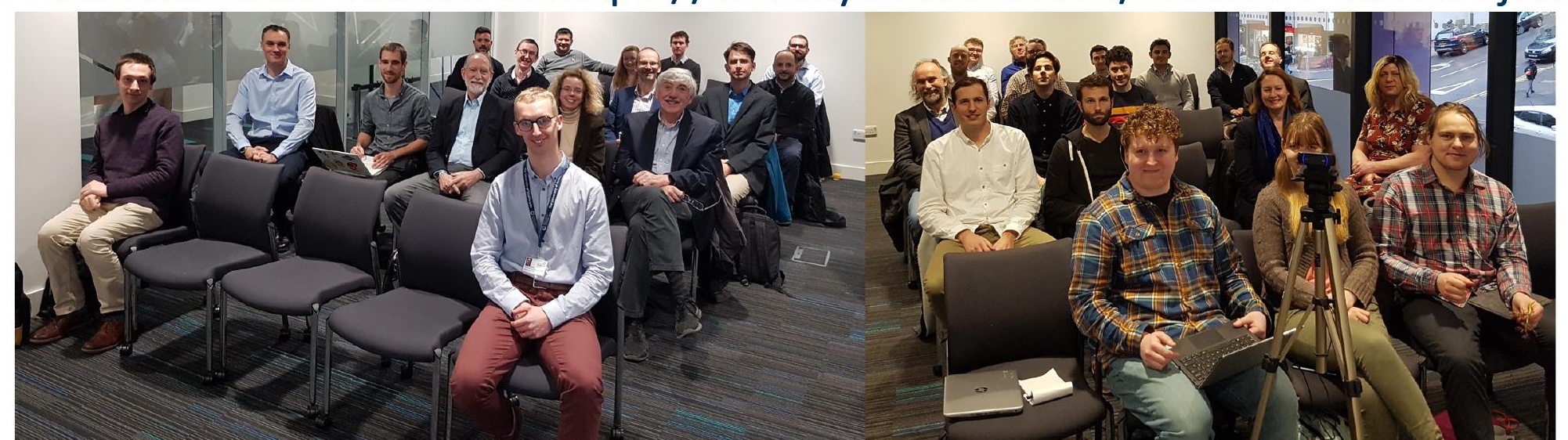


Topic: Meteorological Measurements and Instrumentation Standardization for Integration into Grid Codes

\section{Results from 2 Workshops: ICEM 2019 \& WIW 2019}

\section{Need for Industry Standard ?}

$\rightarrow$ Need for best practices: BUT too strict standards are worse than non

$\rightarrow$ No standards leads to chaotic data management

$\rightarrow$ Instrumentation without maintenance: data looses value

$\rightarrow$ Maintenance schedules: once, twice per year?

$\rightarrow$ Met instrumentation should be part of the turbine delivery/installation

\section{- Dissemination}

- No consensus on how to accomplish

- ENSO-E is a potential body for dissemination

- Forecasting still undervalued. Need more forecasters in TSOs.

o Need simple advice to give operators, especially in the developing world
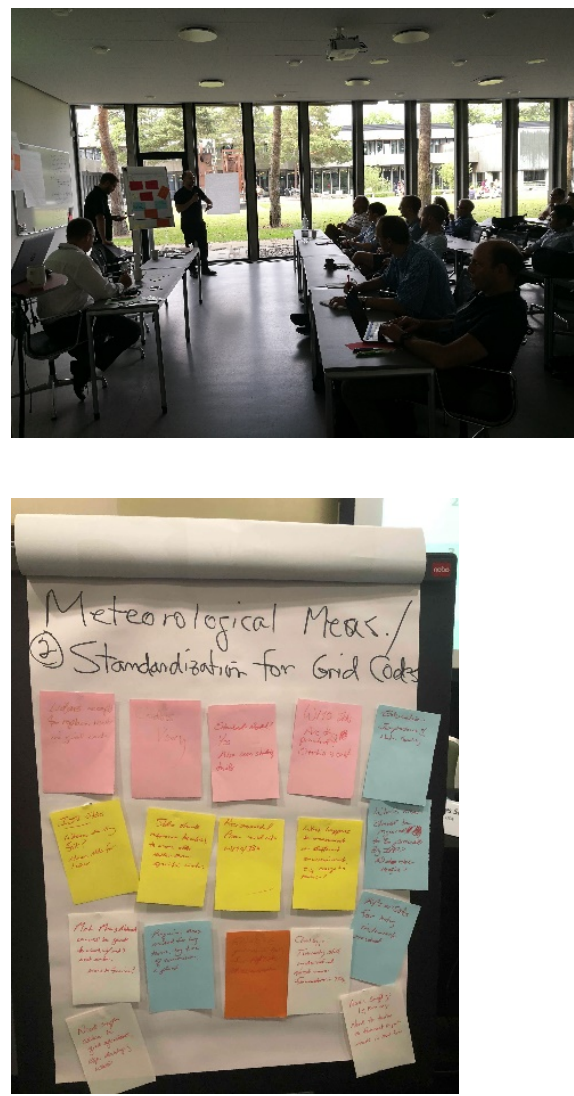
Topic: Meteorological Measurements and Instrumentation Standardization for Integration into Grid Codes

\section{Results from 2 Workshops: ICEM 2019 \& WIW 2019}

- General Agreement that Standards/RPs are Needed

- Grid codes vary from region to region

- Concern about adopting WMO or similar standards, which may be expensive overkill for grid code purposes

o Should reference traceability to standards but be instrument agnostic

- Could suggest required measurements by IPPs at time of commissioning

- Need education on importance of data quality

- Need to address site selection for instrumentation

- Need to tailor reporting interval to forecast model input needs

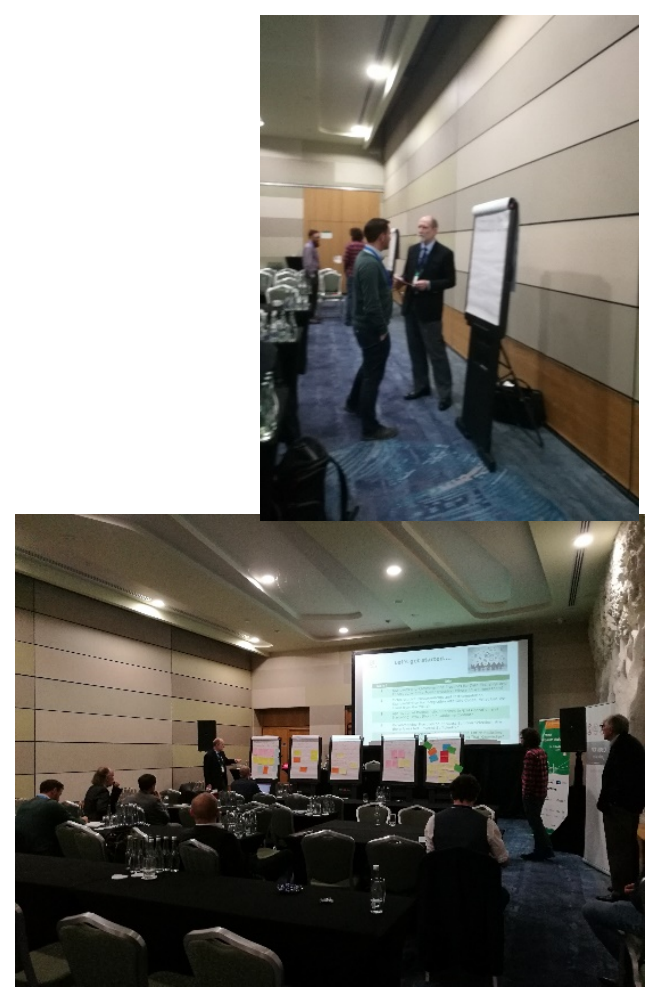




\title{
Data Science for Environmental
}

\section{PRESENTATION SLIDES} ESIG Forecasting Workshop

\author{
Session 8 \\ Jethro Browell \\ (presented by Corinna Möhrlen) \\ June 2018 \\ St. Paul, MN, USA
}




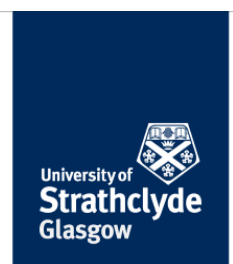

\section{Data Science for Environmental}

Modelling and Renewables

A Massive Open Online Course

6 Weeks, Equivalent to 5 ECTS Credits

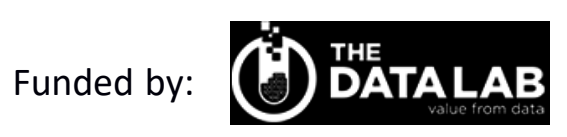

Hosted on: لـ $\begin{aligned} & \text { Future } \\ & \text { Learn }\end{aligned}$

\section{Course Outline}

Week 1: Introduction

Week 2: R Bootcamp

Week 3: Patterns in temporal data

Week 4: Patterns in spatial, spatio-temporal and network data

Week 5: Open data, Citizen Science and Twitter

Week 6: Wind and Solar Power Forecasting

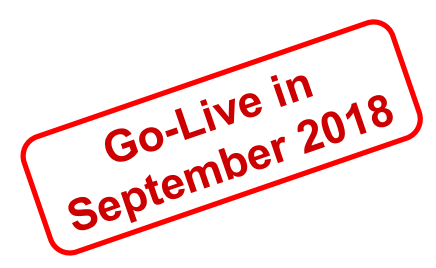




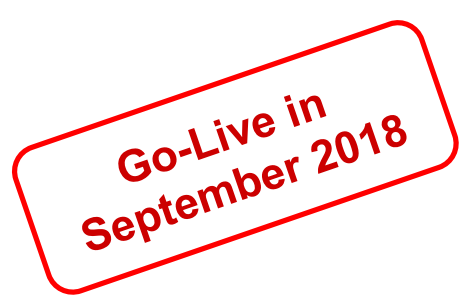

Week 6: Wind and Solar Power

Forecasting

By the end of the week participants will be able to:

- Explain the principles of numerical weather prediction and make informed use of such data

- Produce basic deterministic and probabilistic wind and solar power forecasts

- Explain and apply the principles of forecast evaluation

\section{Tniversity of Glasgow}

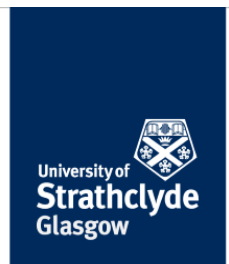

Video Content

30-60 Minutes of video comprising a short lecture and interviews with forecast users.

Content Pages

1. Overview of the model chain: NWP $\rightarrow$

Physical/Statistical Model $\rightarrow$ Use and Evaluation

2. Numerical Weather Prediction: Basic Principles

3. Tools and methods in $R$

4. Deterministic Wind Power Forecasting

5. Principles of Deterministic Forecast Evaluation

6. Deterministic Solar Power Forecasting

7. Introduction to Probabilistic Forecasting

8. Producing Probabilistic Forecasts

9. Principles of Probabilistic Forecast Evaluation

10. Best Practice for Users of Commercial Forecasts 


\section{Statement for Discussion}

Teaching should include standards or guidelines and provide a deeper understanding of the underlying fundamentals

Not having standards leaves teaching at

- fundamental principles

- missing knowledge on state of the art developments

Not having standards educates young professionals with

- very different skills

- no reference to relate new projects to 


\section{Wind power forecasting: IEA Wind Task 36 \& future research issues}

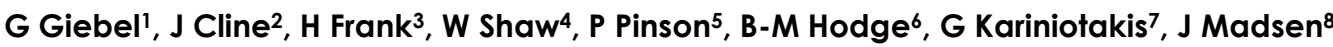
and C Möhrlen'

Published under licence by IOP Publishing Ltd

Journal of Physics: Conference Series, Volume 753, B. Wind, wakes, turbulence and wind farms
Wind power forecasting: IEA Wind Task 36 \& future research issues

G Giebel ${ }^{1}$, J Cline ${ }^{2}$, H Frank ${ }^{3}$, W Shaw ${ }^{4}$, P Pinson ${ }^{5}$, B-M Hodge ${ }^{6}$, G Kariniotakis $^{5}$ J Madsen ${ }^{8}$ and $C$ Möhrlen ${ }^{9}$

${ }^{1}$ DTU Wind Energy, Risø, Frederiksborgvej 399, 4000 Roskilde. Denmark

${ }^{2}$ Department of Energy, Wind and Water Power Program, 1000 Independence Ave.
SW, Washington DC 20585, USA

${ }^{3}$ Deutscher Wetterdienst. Frankfiuter Str. 135, D-63067 Offentach, Germany

${ }^{4}$ Pacific Northwest National Laboratory, 902 Battelle Boulevard, P.O. Box 999, MSIN K9-30, Richland, WA 99352 USA

${ }^{5}$ DTU Elektro, Ørsteds Plads, 2800 Kgs. Lyngby. Denmark

${ }^{6}$ National Renewable Energy Laboratory, 15013 Denver West Parkway, MS ESIF 200

Golden, CO 80401, USA

MINES ParisTech, PSL Research University, Centre PERSEE, CS 10207, 1 Rue

Claude Daunesse, 06904 Sophia Antipolis Cedex, France

VVattenfall AB, Jupitervej 6, DK-6000 Kolding, Denma

E-mail: grgi@dtu.dk

Abstract. This paper presents the new International Energy Agency Wind Task 36 on Forecasting, and invites to collaborate within the group. Wind power forecasts have been use operatively for over 20 years. Despite this fact, there are still several possibilities to improve new Internation Enery Agency (IEA) Task on Fereasting for Wind Energy tries to new International Energy Agency (inA) Oask on Forecasting for Wind Energy tries to organise projects on wind forecast improvements (NOAA, DWD, Metoffice, met.no, DMI, ...) operational forecaster and forecast users. 


\section{Collected Issues}

Nowcast (especially for difficult situations, thunderstorms, small lows, ...)

Sub 1 hour temporal resolution

Meteorology below $1 \mathrm{~km}$ spatial resolution

Stability issues, especially with daily pattern / (Nightly) Low level jets

Icing

Farm-Farm interaction / quality of direction forecast

Short-term ensembles

Ramps and other extremes

Spatio-temporal forecasting

Rapid Update Models (hourly, with hourly data assimilation)

Use of probabilistic forecasts and quality of the extreme quantiles

Do DSOs need different forecasts than TSOs?

Penalties for bad performance? Incentives for improved perf.?

Seasonal forecasting? What's the business case?

Data assimilation (with non-linear Kalman filters, 4D Var, ...) 
